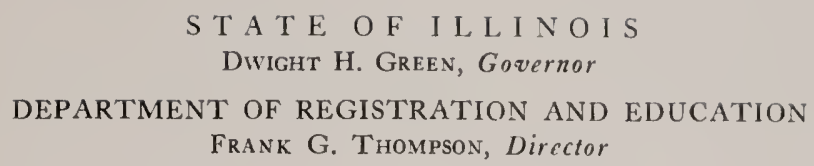

\begin{tabular}{lll}
\hline Volume 22 & B ULLE T I N & Article 7 \\
\hline
\end{tabular}

\title{
Illinois Furbearer Distribution and Income
}

\author{
C A R L O . M OHR
}

Printed by Authority of the State of Illinois

\author{
URBA N A, I L L I N O I S \\ September 1943
}




\begin{tabular}{|c|c|}
\hline & $\begin{array}{r}\text { Page } \\
506\end{array}$ \\
\hline Numbers of Fur-Takers. & .507 \\
\hline Comparison of Data. ........ & 511 \\
\hline Trends in Furbearer Catch. . & 511 \\
\hline Distribution Patterns of Furbearers. & .512 \\
\hline Múgkat.... & 513 \\
\hline Distribution... & .513 \\
\hline Trappers, Catch and Income. & .513 \\
\hline Mink. & .514 \\
\hline Distribution. . & 514 \\
\hline Trappers, Catch and Income. & 515 \\
\hline RACCOON. & .516 \\
\hline Distribution......... & 516 \\
\hline Trappers, Catch and Income. & .516 \\
\hline SKUNK. . & .517 \\
\hline Distribution. & .517 \\
\hline Trappers, Catch and Income. & .518 \\
\hline Opossum................ & .518 \\
\hline Distribution.... &. .518 \\
\hline Trappers, Catch and Income. & .519 \\
\hline Foxes... & .520 \\
\hline Distribution. . & .520 \\
\hline Trappers, Catch and Income. & .521 \\
\hline Numbers of Red Foxes Caught. & ...522 \\
\hline Income from Red Foxes... &. .523 \\
\hline Numbers of Gray Foxes Caught. & .523 \\
\hline Income from Gray Foxes...... & .523 \\
\hline LONG-TAILED WEASEL $\ldots \ldots \ldots$ &. .523 \\
\hline Distribution.......... & .523 \\
\hline Trappers, Catch and Income. & .524 \\
\hline LEAST VEASEL. &. .524 \\
\hline BaDger. & .525 \\
\hline Distribution. . &. .525 \\
\hline Catch....... & .526 \\
\hline Вовсат..... &. .526 \\
\hline Domestic Cat........ & $\ldots 527$ \\
\hline Otter..................... &. .527 \\
\hline Сочоте.................. & $\ldots 528$ \\
\hline Marten......... & .532 \\
\hline Spotted Skunk.... &. .532 \\
\hline Beaver.......... & .533 \\
\hline Total annual Catch. &. .534 \\
\hline Total Annual Income.... &. .535 \\
\hline Future Possibilities........ & $\ldots 536$ \\
\hline Literature Cited . . . . . . . . . . & $\ldots 536$ \\
\hline
\end{tabular}




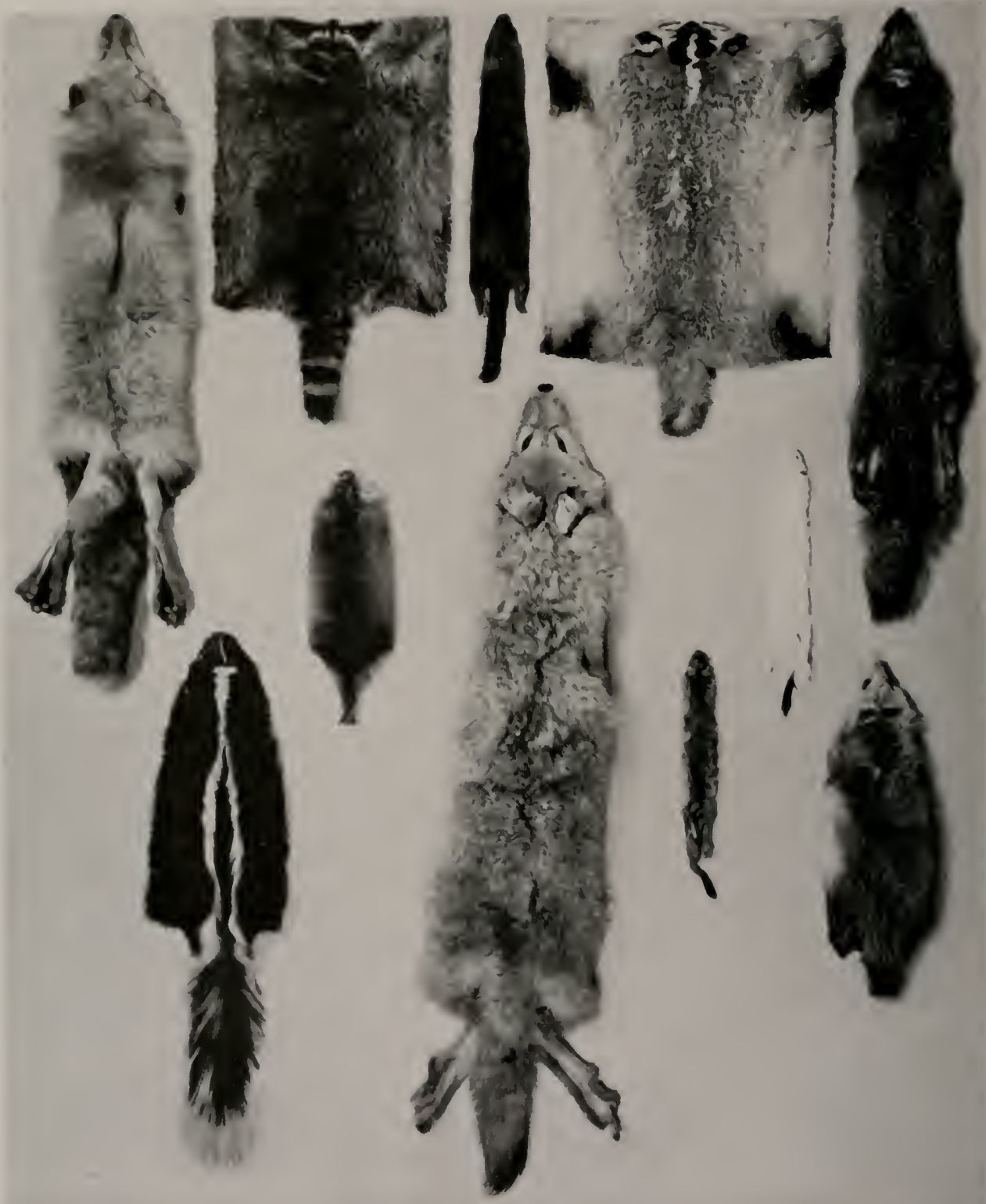

Representative pelts of Illinois fur animals. Left to right, top roz:, red fox, raccoon, mink, badger and gray fox; lower row, skunk, inuskrat, coyote, long-tailed weasel (brown phase), long-tailed weasel (white phase), opossum. The muskrat ranks first, both in number of pelts and in total value in the Illinois catch; second in number is the opossum, but second in total value of catch is the mink. Third in total value is the raccoon. The most valuable pelt produced by Illinois fur-bearing animals is that of the mink. The skunk pelt shown is the narrow stripe grade. Because of its scarcity, the badger is now protected the year around in Illinois. 


\section{Illinois Furbearer}

\section{Distribution and Income}

\section{A R I. O . M O H R}

$\mathrm{F}$ OR more than a century after Illinois became a state, stock-taking of its renewable natural resources was conducted only irregularly and, in some instances, was not attempted until after serious shortages had become apparent. Those components which, like furbearers, provided but a comparatively small part of an immense state income received scant and casual attention. Within the past few years, however, efforts to evaluate all components have become serious, and these efforts have gained strength as the true value of the resources has become apparent.

About 30 years ago, Dr. Stephen A. Forbes (1912), former Chief of the Illinois Natural History Survey, quoted United States census figures for 1910 , stating that the annual yield of mink pelts in Illinois was valued at $\$ 6,000$ and the yield of muskrat pelts at $\$ 1+, 000$. He did not quote income from the other furbearer species. No data regarding the total annual furbearer catch appeared to be available.

Neither technical nor popular interest was great enough to focus further attention of the state's research agencies on furbearers until, in 1930, David H. Thompson, E. C. Driver and D. I. Rasmussen of the Illinois Natural History Survey staff borrowed trappers' reports, fig. 1 , from the Illinois State Department of Conservation, to which law provided that each licensed trapper report his catch monthly during the trapping season. These reports, stating the monthly catch of a limited number of trappers for the 1929-30 and 1930-31 seasons, were summarized by the Survey in cooperation with the Department of Conservation; data on these reports are in an unpublished manuscript by Driver (1930) and in unpublished notes by Rasmussen (1931).
The estimated income from important furbearer species was included by Dr. T. H. Frison, Chief of the Illinois Natural History Survey, in several administrative reports (Frison 1931, 1933), most detailed of which was in the Blue Book of the State of Illinois, 1931-1932. In this report, Dr. Frison (1931) stated that for the 1929-30 season the total income of licensed Illinois trappers from the seven most important furbearers was estimated at $\$ 957,651$; almost half of this amount from the sale of muskrat pelts and almost a third from the sale of mink pelts. After allowing for the sale of pelts by fur-takers not required to purchase trappers' licenses, he estimated that "the actual value of the fur vield in Illinois-not including fur farming-must approach at least two millions of dollars." A few years later, Dr. Frison (1938) stated that data at hand indicated an income from the state's furbearers "of one million to two million dollars a year."

A lapse of 3 years followed the studies by Thompson, Driver and Rasmussen, after which the writer prepared data on the state's furbearers for the Natural History Survey's files, using as his source fur-takers' reports made monthly during the trapping season to the State Department of Conservation, from which the writer borrowed them. Later, the writer (1937,1939, 1941), using the same source of information, reported on the distribution of muskrats, coons and possums in Illinois, and on fluctuations in the state's furbearer catch. Also, the Department of Conservation abstracted the fur-takers' reports for certain years; this agency's figures were mimeographed and distributed by the U. S. Bureau of Biological Survey (1939) and its successor, the U. S. Fish and Wildlife Service $(19+0)$ in wildlife leaflets. 
According to these leaflets, the total annual catch of fur species in Illinois iaried from 238,311 animals in the 1934 35 season to 996,998 in the $1938-39$ season. As will he seen later, most of the figures were extremely conservative because up to the season of 1938-39 they failed to take into account the great and unknown numbers of unlicensed trappers. Beginning with the 1938-39 season, figures were revised upward because of preliminary findings of the oral survey, detailed results of which are summarized in the Brown \& Yeager report.*

Serious difficulties lay in the way of attaining fully satisfactory total-kill figures from fur-takers' monthly reports made previous to the 1938-39 season. No reliable data on the number of trappers and fur-hunters who operated without licenses, nor on the size of their catch, were available until after adoption of the so-called Pittman-Robertson program in Illinois. As explained in the Brown \& Yeager report, Louis G. Brown, leader of a Federal Aid furbearer survey, interviewed trappers, fur-hunters and fur-buyers in 10 counties typical of various regions in Illinois (fig. 2 of Brown \& Yeager report) and obtained figures for an estimate of yield in the seasons of 1938-39 and 193940. Brown also gathered supplementary data which permitted re-evaluation of yield data derived in the past by the writer from fur-takers' reports made monthly during the trapping season, but he could not obtain more than general impressions from fur-takers about the trend of furbearer catch or populations. In general, fur-takers believed that most species had declined in numbers.

Neither could Brown find time to discover much about the distribution of the less valuable fur-producing species nor about special concentrations of any of the fur-producing species. It goes without much discussion that the distribution of the different species is far from uniform in the sample areas defined and used, each species having a distribution pattern different from that of each of the others. The various distribution patterns cut across the sample areas in every conceiv-

-In the present paper, the terms oral suries or Brown's surtery are used to designace the furbeares survey made by Louis G. Brown, results of which are contained in the repost ofeen teferted io here as the Brosen ${ }^{\prime}$ Yeager report. published with this paper as Aricle 6. able order, as shown by the oral survey and, in greater detail, by data from furtakers' monthly reports. (Compare fig. 2 in Brown $S$ Yeager report with the distribution maps in the following pages.)

Distributional information and annual catch data derived from fur-takers' monthly reports are at hand for most of the trapping seasons beginning with 1929-30 and ending with 1939-40 and are here recorded, along with records of the number of licensed fur-takers and estimates of their catch. After being compared with findings of the oral survey, raw data derived from the fur-takers' monthly reports were revised in such a way as to show better than heretofore how the value of the fur catch has stood from year to year. Data for the seasons of 1931-32, 1932-33 and 1933-3t were not available to the writer, and these seasons therefore could not be considered in this study.

\section{ACKNOWLEDGMENTS}

The writer is indebted to the Hon. Livingston E. Osborne, present Director of the Illinois State Department of Conservation, and to Mr. Thomas J. Lynch and the late Mr. C. F. Thompson, former directors, for loan of fur-takers' monthly and annual reports, as well as to $\mathrm{Mr}$. Lewis E. Martin and Mr. J. V. Maloney, formerly of that Department.

Students working under the Federal Emergency Relief Administration and the National Youth Administration assembled most of the data in these reports. Mr. Roy G. Wiesbrock, commerce student at the University of Illinois, aided greatly in final analysis of these figures in 1942 as they were being prepared for publication. During previous years, other University of Illinois students, Mr. WValter J. Godelausky and Mr. Howard C. Shepherd, had assembled and calculated many of the returns.

Many members of the Natural History Survey's-Aquatic Biology and Wildlife sections furnished aid and advice. Dr. David H. Thompson, who directed analysis of the 1929-30 and 1930-31 data, Dr. Lee E. Yeager, Dr. R. E. Yeatter and Mr. Louis G. Brown were most closely consulted in strictly technical matters relating to this report.

The photograph used as a frontispiece 
was furnished by Sears, Roebuck and Company, Chicago.

\section{NUMBERS OF FUR-TAKERS}

In the seasons before 1937-38 covered by this report, the state game code provided that each Illinois fur-taker* operating on land on which he did not reside must buy a trapping license if he took his catch with traps, or a hunting license
As will be explained below, the ratio of unlicensed to licensed trappers was probably about 1.5 to 1.0 during the period beginning with the $1929-30$ season and lasting through the 1937-38 season, fig. 2 and table 1. After that it decreased because of changes in the game code recorded below and improvement in conservation sentiment.

In the years covered by this report, the number of licensed fur-takers in Illinois
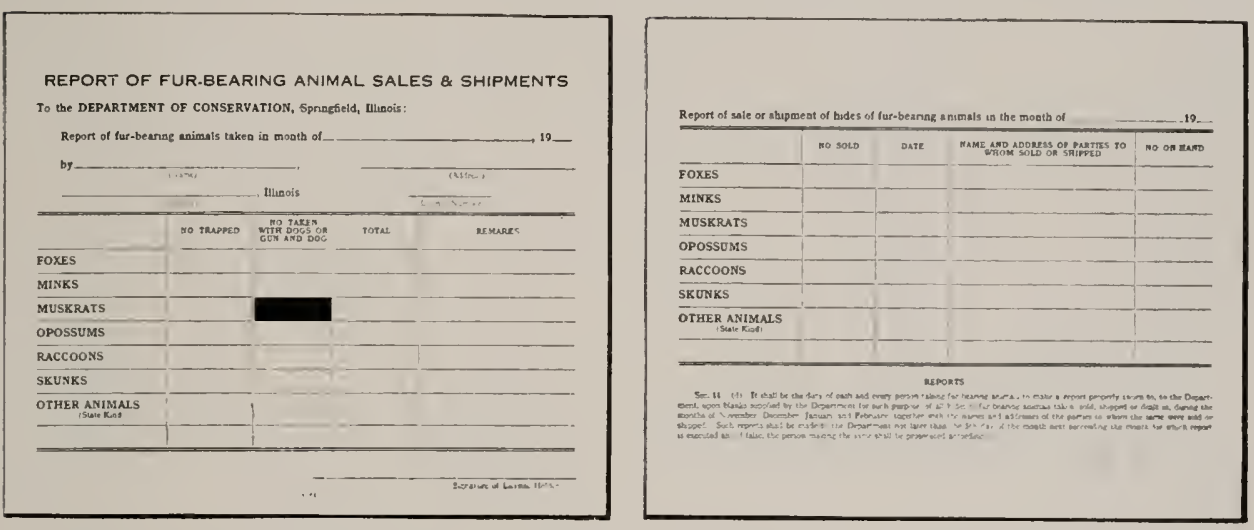

Fig. 1. -The two sides of the form on which the Illinois game code provided that fur-takers were to make monthly reports of their catch of fur-bearing animals to the State Department of Conservation for the 1938-39 season. Part of the code read as follows: "It shall be the duty of each and every person taking fur-bearing animals to make a report properly sworn to, to the Department, upon blanks supplied by the Department for such purpose, of all hides of fur-bearing animals taken, sold, shipped or dealt in, during the months of November, December, January and February... Such reports shall be made to the Department not later than the 5th day of the month next succeeding the month for which report is executed." The code for 1935-36 had read "each and every holder of a trapping license" instead of "each and every person taking fur-bearing animals."

if he took furbearers by hunting. If the fur-taker operated solely under a hunting license, he was not required to report his catch. If, however, he operated under a trapping license, the law provided that he report all of his catch monthly during November, December, January, February and March on a form, fig. 1, supplied by the State Department of Conservation. If the fur-taker trapped only on farm land on which he resided, he was required neither to buy a license nor to report his catch. Because of numerous loopholes that made law enforcement difficult, the percentage of licensed trappers who reported was low and varied annually, table 1 .

*The term fur-taker, as used in this report, usually includes both fur-trappers and fur-hunters. has varied from $6,+80$ to a calculated 16 ,615 , being highest for the $1939-40$ season, table 1 . The average annual number has been about 11,300 , or roughly 110 per county.

Frison (1931), in assuming that the income of the unlicensed fur-takers operating in Illinois during the $1929-30$ season was about as great as that of the licensed fur-takers, by implication set the total number of fur-takers at twice the 13,911 reported for the season. A similar procedure in making fur-taker estimates has since been general practice in Illinois, for the sake of being conservative, although the feeling has been common that the ratio of unlicensed to licensed trappers was greater than 1 to 1 .

After Brown had made the oral survey 
in 10 representative counties in Illinois, he and Yeager calculated that $29,+31$ furtakers had operated in the state during the 1938-39 season, table 1 ; also table 4
The second change provided that each fur-taker, whether or not he held a license, report his catch monthly during November, December, January and February on

Table 1.-Data on licensed, unlicensed and total fur-takers in Illinois.

\begin{tabular}{|c|c|c|c|c|}
\hline SEASON & $\begin{array}{l}\text { Number of } \\
\text { licensed } \\
\text { lur-Takers }\end{array}$ & $\begin{array}{l}\text { Calculated } \\
\text { Number of } \\
\text { Unlicensed } \\
\text { liur-Takers }\end{array}$ & $\begin{array}{l}\text { Calculated } \\
\text { lotal. Number } \\
\text { of Fur-Takers }\end{array}$ & $\begin{array}{c}\text { Per Cent of } \\
\text { IACENSED } \\
\text { Fur-Takers } \\
\text { Reporting on } \\
\text { Monthly Forms }\end{array}$ \\
\hline $\begin{array}{l}1929-30 \ldots \\
1930-31 * \ldots \\
1934-35 \ldots \\
1935-36 \ldots \\
1936-37 \ldots \\
1937-38 \ldots \\
1938-39 \ldots \\
1939-40 \ldots \\
\text { Average .... }\end{array}$ & $\begin{array}{c}13,911 \\
11,575 \\
6,654 \\
6,480 \\
9,815 \\
12,560 \dagger \\
12,810 \dagger \\
16,615 \dagger \\
11,303\end{array}$ & $\begin{array}{c}20,867 \\
17,363 \\
9,981 \\
9,720 \\
14,723 \\
18,840 \\
16,621 \ddagger \\
10,406 \ddagger \\
14,815\end{array}$ & $\begin{array}{l}34,778 \\
28,938 \\
16,635 \\
16,200 \\
24,538 \\
31,400 \\
29,431 \ddagger \\
27,021 \ddagger \\
26,118\end{array}$ & $\begin{array}{l}15 \\
10 \\
13 \\
14 \\
11 \\
23 \\
18 \\
11\end{array}$ \\
\hline
\end{tabular}

- Data for the 1931-32,1932-33 and 1933-34 seasons were not available to the writer.

tThese figures were calculated from fur-takers' reports. The average number of licenses per licensed fur-taker was about 1.2, 1.2 and 1.1 in 1937-38, 1938-39 and 1939-40, respectively. Before the 1937-38 season, each fur-taker bought not more than one license.

$¥$ These figures are estimated on the basis of data from the oral survey by Brown.

of Brown \& Yeager report. The number of licenses, as calculated from fur-takers' reports, was 12,810 for the season; about 1.27 times as many fur-takers had operated without as with licenses, exceeding the earlier ratio estimates for previous years by 0.27 .

The oral survey indicated that, during the 1939-40 season, 27,021 fur-takers had operated when, monthly reports seemed to show, 16,615 fur-takers had held licenses. The number of licensed fur-takers exceeded the number of those unlicensed, and the ratio of unlicensed to licensed fur-takers was 0.63 to 1.00 .

Six changes in the game code, the first five made in 1937 and the sixth in 1939 , so altered trapping conditions as to make the ratios of unlicensed to licensed trappers for the 1938-39 and 1939-40 seasons much too conservative to apply to the seasons preceding them.

The first change, in force by the beginning of the 1937-38 trapping season, provided that each person taking fur-bearing animals, by any method whatsoever, on land on which he did not reside, must purchase a fur-taker's license (Illinois State Department of Conservation 1935 , 1937 ). a form, fig. 1, furnished by the State Department of Conservation.

The third change provided that each applicant for a license, at the time of making his application, report on an annual form, fig. 3, supplied by the State Department of Conservation, the number, or quantity, and species of fur-bearing animals taken by him the next preceding year.

The fourth change provided that each fur-taker trapping on land on which he did not reside must purchase a license for each 25 traps, or fraction of that number, and that each fur-taker operating on the farm land on which he resided must purchase a license for each 25 traps, or fraction of that number, in excess of the first 25 traps to which residence on the land entitled him.

The fifth change provided that each licensed fur-taker identify his traps by means of numbered tags obtained from the State Department of Conservation. This change assisted game wardens in distinguishing legal from illegal trapping and forced the purchase of licenses by some of the trappers who had previously been able to evade the law.

The 1937 code changes were effective in 
bringing to record about 2,400 fur-hunters who had previously reported neither themselves as fur-takers nor the amount of their catches. The number of reporting furhunters rose from a previous annual high of 15 per cent of the reporting fur-takers (about 1,500 individuals) in 1936-37 to 30 per cent (about 3,900 individuals) in 1937-38.

The sixth change in the code, in force beginning with the 1939-40 season, plugged another loophole by providing that each unlicensed, as well as licensed, trapper must tag all of his traps (1llinois State Department of Conservation 1939).
This provision apparently was responsible for much of the numerical difference between the 12,810 fur-takers licensed during the 1938-39 season and the 16,615 licensed during the 1939-40 season, and for the reduction in the ratio of unlicensed to licensed trappers. It brought to record probably about 4,000 trappers who the previous year had not been recorded.

With the six changes in the law mentioned above, the number of licensed trappers increased from 9,815 in 1936-37 to a calculated 16,615 in $1939-40$, an increase of 6,800 , indicating that if these changes had not been made the ratio of

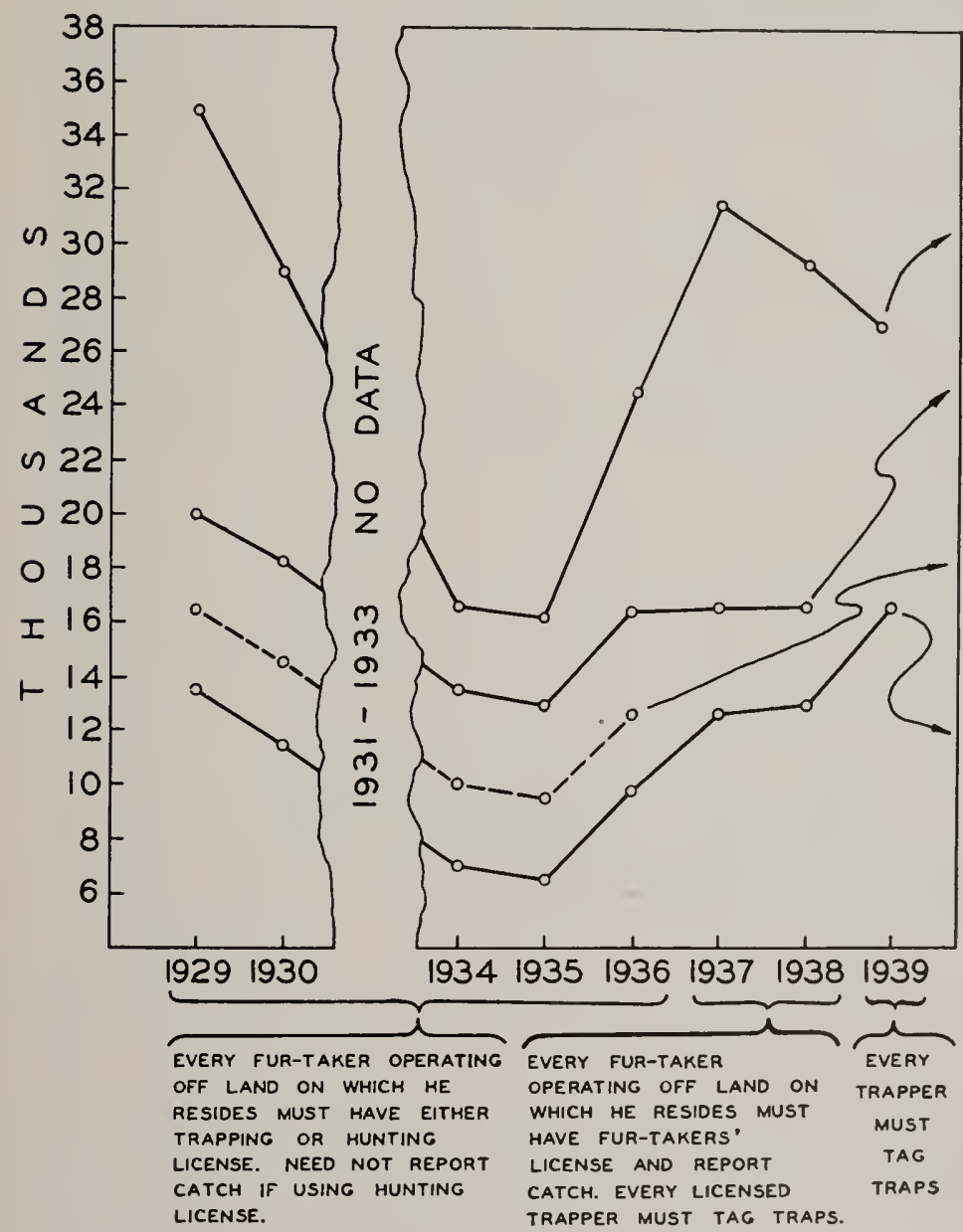

ESTIMATED TOTAL NUMBER OF FURTAKERS.

ESTIMATED NUMBER OF FUR - TRAPPERS REQUIRED BY LAW TO BUY LICENCES.

ESTIMATED NUMBER OF FUR-HUNTERS REQUIRED BY LAW TO BUY LICENCES.

NUMBER OF LICENSED FUR - TAKERS.

Fig. 2.-Graph showing the number of licensed fur-takers, estimated number of fur-hunters required by law to buy licenses, estimated number of fur-trappers required by law to buy licenses, and estimated total number of fur-takers for eight trapping seasons included in the present study. Each trapping season is indicated by only one date; for instance, the trapping season of 1929-30 is represented by the date 1929. The graph illustrates the effect of changes in the code. 
licensed to unlicensed trappers would have been about 1.00 to 1.50 instead of 1.00 to 1.27 , as found after the oral survey in Illinois, in each of the seasons covered by this report, we arrive at close approximations of the total number operating in

This application to be sent each month with remittance to Department of Conservation. Springfield

\section{No. U 12101 To take Fur Bearing Animals License-Resident}

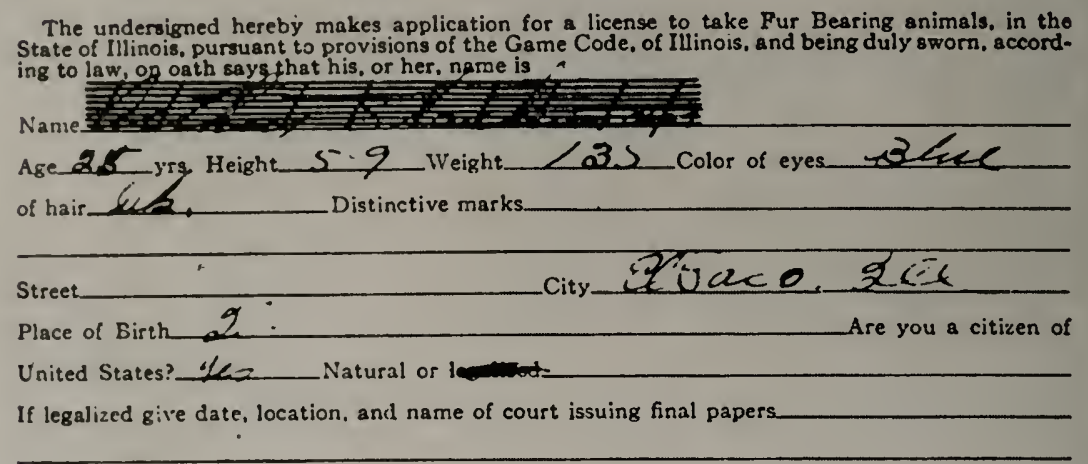

If applicant is a minor child of a naturalized citizen. date of final naturalization papers of his or her father, and the name and location of court which issued same are as follows:

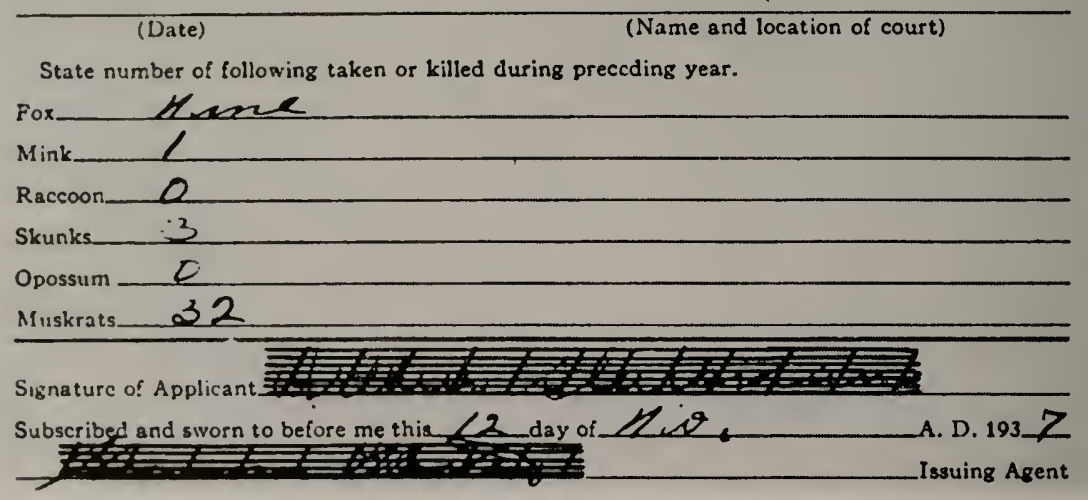

Fig. 3.-Application for Illinois fur-taker's license for use in the 1937-38 season. The game codes of 1937 and 1939 specified that the applicant state the number of certain fur-bearing animals taken or killed by him the preceding year.

was begun following the 1937 revision, and 1.00 to only 0.63 , as found after the 1939 revision. 'The estimated numbers of unlicensed fur-takers for years of this study previous to the 1938-39 season are based on the ratio of 1.00 licensed furtaker to 1.50 unlicensed fur-takers.

By adding the known or calculated number of licensed fur-takers to the calculated number of unlicensed fur-takers those seasons, table 1 and fig. 2. Calculations for the 1938-39 and 1939-40 seasons are based in part on data obtained by the oral survey.

Calculations recorded in table 1 indicate that the lowest number of fur-takers operating in Illinois during any one season covered by this report has not been less than 16,200 and that the average annual number has been 26,118 . La Due (1935) 
published a map with figures, credited to the National Fur Tax Committee, indicating that the "number of trappers" in Illinois was 132,990 , but these numbers were perhaps misquoted and are certainly erroneous. Calculations for the seasons reported here set the average annual number of trappers at about 256 per county, an average of slightly less than 1 to each 2 square miles. The number was exceeded considerably in the season of 1929-30, when the average per county was about 340 , and it was exceeded also in the 1930 $31,1937-38,1938-39$ and $1939-40$ seasons. The numbers are, of course, greatest in those counties where trapping is most profitable or where such game-fur animals as coons and foxes provide extensive sport.

\section{COMPARISON OF DATA}

The Brown \& Yeager study was designed in part to obtain a check on the accuracy and usefulness of data based on fur-takers' monthly reports, which were being used for studying (1) trends in the Illinois furbearer catch over a period of years and (2) distribution patterns of furbearers. When the 10 counties were selected as sampling grounds representing widely varying conditions in widely scattered regions in Illinois (fig. 2 of the Brown \& Yeager report), it was known that the resulting figures would not coincide with those from the fur-takers' monthly reports, but the probability of similarities was recognized. We wished to find the nature and extent of both similarities and differences.

Trends in Furbearer Catch.-For making annual comparisons between figures from the oral survey and those from the fur-takers' monthly reports, two methods of working up raw data from the monthly reports were attempted. The first method involved, for each important furbearer, a calculation by counties of (1) the percentage of fur-takers who, on the monthly report blanks, reported catching that fur-bearer and (2) the reported average catch per effective fur-taker* of that furbearer; these figures were then weight-

* As used in this report, the term effective fur-taker refers to a person who, in the season or seasons under consideration, has caught at least one individual of the furbearing species being discussed. Thus, a fur-taker who in a given year has caught muskrats but no other fur species is regarded in that year as effective for muskrats only. ed according to the relative size of the counties.

The second method, which was finally rejected, involved a calculation for the state as a whole of the percentages and averages mentioned in the first method; no weighting was done.

Weighted data derived from the first method were less subject to local law enforcement irregularities than were data from the second, and they corresponded closely with figures calculated from data accumulated for the Brown \& Yeager report.

Data from this first method, such as that contained in table 2 and similar tables, can therefore be used as index figures by which changes in effective furtakers and catch can be measured over a period of years. These figures, hereafter usually referred to as monthly report index figures, are believed to be the most useful obtainable to indicate trends oz'er a period of several years, because up to the season of 1938-39 it had not been possible to trace by any other means the changes in numbers of fur-takers in the several parts of Illinois.

The monthly report index figures show the greatest deviation from figures derived from the oral survey in the case of muskrats. For the 1938-39 season, the difference was 7 points and during the following season it was 10 points. Figures for most of the other furbearers deviated only 4 points or less. We believe that the deviation is not so great as to invalidate general conclusions about the average annual catch, or fluctuations in the catch from year to year.

Numerical differences between the data derived from the oral survey and those from fur-takers' monthly reports are to be expected. It is probable that the relatively small number of fur-takers represented by the monthly reports, table 1 and fig. 2, is selective and therefore not representative of the whole group. It is plain, too, that weighting the data from the monthly reports by area does not weight them according to the total number of trappers, which would be a better weighting factor if it could be obtained.

The monthly report figures represent several seasons, include trappers in every county in the state, and of necessity take into account only those trappers who ac- 
tually reported. The oral survey data, as explained in the Brown \& Yeager report, represent two seasons, cover 1.7 per cent of the area of the state and include within the strips actually surveyed all trappers, licensed and unlicensed, those who reported and those who did not.

Despite numerical differences, correlations between the monthly report index figures and the oral report data, for both average catch per fur-taker and percentage of fur-takers catching a given furbearer, is such as to provide valuable information regarding trends in catch.

The differences between the two sets of data are found to be largely in level, and similarities to consist chiefly of parallelisms. In other words, though differences exist, positive correlations are found in figures from the two studies.

Distribution Patterns of Furbearers.-In general, it is true that the size of the average catch per fur-taker of a given furbearer correlates closely with the size of the population of that furbearer. After calculating for any furbearer species the average catch per fur-taker, we can transfer the resulting data to a map in such a way as to give us a logical and useful graphic representation that is a good clue to combined dispersion and abundance of the animal.

Such a map has been made for each of the common furbearers discussed in this study. These maps are the best clues we have to the distribution pattern of furbearers in all lllinois counties. On these maps, the calculated figures are converted into dots in such a way that the county having the largest average catch in a given species is most heavily dotted, and other counties are dotted proportionately. Each species is considered separately, and the maps do not indicate relative abundance as among species; for instance, although the distribution map for minks is about as heavily stippled as that for muskrats, these maps are not intended to suggest that the catch of minks is as large as that of muskrats. Eight seasons of fur-takers' recurds are summarized on the maps, the first of which is shown in fig. $t$.

These distribution maps indicate to what extent one set of data (from the oral survey showing average catch per square mile for two seasons) parallels or correlates with another set of data (from the fur-takers' monthly reports showing average catch per fur-taker for eight seasons). On these maps, oral report data are shown as numerals; as stated above, fur-takers' written. report data are represented by dots. Comparison of the two sets of data reveals a close correlation.

It will be seen that the distribution pattern of no two species is exactly alike and in most cases is not even similar. Each species is a law unto itself in this matter. Its distribution does not conform completely to any easily apparent physical or agricultural characteristic of the land, and management must take into account this lack of conformity.

The scope of this study did not permit construction of separate dispersion and localized abundance maps, which would show facts that the distribution, or combined dispersion-abundance, maps do not portray: whether the furbearer populations are widely dispersed and small, narrowly dispersed and small, widely dispersed and large, or narrowly dispersed and large. From a management point of view, each of these cases is important.

In constructing a dispersion map, we first calculate the percentage of fur-takers who trapped a given species in each county, or other relatively small geographical unit; then we transfer the data to a map by use of dots and find a logical and useful pattern showing what proportion of furtakers in any given area caught that particular species. Such a map furnishes a good clue to the dispersion of the furhearer. If, in a given area, only a small proportion of the fur-takers caught the species, there is every likelihood that this species was not so widely distributed as in some area in which a large proportion of fur-takers caught it.

In constructing a localized abundance map, we first calculate for any given species of furbearer the average catch per effective fur-taker, transfer these data to a map by use of dots and again find a logical and useful pattern. A map of this kind will be somewhat different from the dispersion map because it will show not the proportion of fur-takers who caught the furbearer but the size of the average catch. Such a map furnishes a useful clue to the abundance of any furbearer in small, localized areas where it is present. If the average catch of a given 
furbearer in a given area is large, the population of the furbearer in that area is very likely to be large, and, if small, the population is likely to be small.

\section{MUSKRAT*}

Distribution.-Muskrats, fig. 4, are present in every Illinois county and are most numerous in Lake and McHenry counties, north of Chicago, where ponds, marshes and herb-lined lakes and slow, stable streams are at once widespread and excellent habitats. With some exceptions the numbers of muskrats diminish gradually to the west and south until, in the very southernmost counties, where the

Table 2.-Weighted per cent of Illinois furtakers who reported catching muskrats, and weighted average catch of muskrats per effective fur-taker; data derived from fur-takers' monthly reports, and weighting done on the basis of the relative size of the counties rep. resented in the years for which records are available.

\begin{tabular}{|c|c|c|}
\hline SEASON & $\begin{array}{l}\text { Weighted } \\
\text { Per Cent } \\
\text { of } \\
\text { Fur-Takers } \\
\text { Catching } \\
\text { Muskrats }\end{array}$ & $\begin{array}{c}\text { Weighted } \\
\text { Average } \\
\text { Catch of } \\
\text { Muskrats Per } \\
\text { Effective } \\
\text { Fur-Taker }\end{array}$ \\
\hline $\begin{array}{l}1929-30 \ldots \\
1930-31 \ldots \\
1934-35 \ldots \\
1935-36 \ldots \\
1936-37 \ldots \\
1937-38 \ldots \\
1938-39 \ldots \\
1939-40 \ldots \\
1940-41 \ldots \\
1941-42 \ldots\end{array}$ & $\begin{array}{l}81 \\
83 \\
85 \\
91 \\
86 \\
70 \\
73 \\
75 \\
70 \\
63\end{array}$ & $\begin{array}{l}22 \\
25 \\
26 \\
23 \\
24 \\
28 \\
30 \\
31 \\
33 \\
30\end{array}$ \\
\hline
\end{tabular}

swamps and the violently fluctuating streams are highly unfavorable, these furbearers are almost rare. A Champaign County muskrat is shown in fig. 5.

Figures from the oral survey indicate that the catch of muskrats in Lake County was about 26 times as great as that in Union County during the 1938-39 and 1939-40 seasons.

\section{Trappers, Catch and Income.-As}

* The scientific nanies of fur animals mentioned in this paper are listed facing the contents page of the Brown \& Yeager report. shown in tahle 2 , the index figures derived from the monthly reports for per cent of fur-takers catching muskrats increased gradually from 81 in the $1929-30$ season to 91 in the 1935-36 season, after which they declined to 63 in the 19+1-42 season.

Monthly report index figures for the per cent of fur-takers catching muskrats are 7 and 10 points lower for the 1938-39 and 1939-40 seasons, respectively, than the figures derived from data assembled during the oral survey.

The index figures derived from the

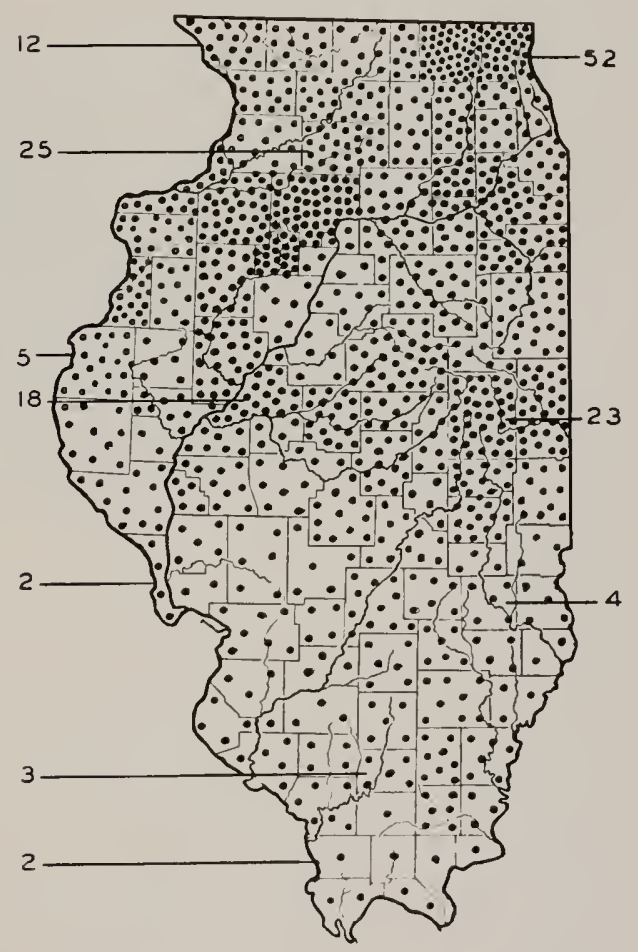

Fig. 4.-Distribution of muskrats in 1llinois as indicated by fur-takers' monthly reports for the seasons of 1929-30, 1930-31 and 193+-35 through 1939-40. Data from these eight seasons of monthly reports have been transferred to the map in such a way that the county having the largest average catch per fur-taker has the greatest density of dots; other counties are dotted proportionally. The numbers in the margins represent for each county indicated the average catch per square mile as revealed by Brown's survey for the 1938-39 and 1939-40 seasons. In general, a close correlation exists between the two sets of data, despite the fact that one is for eight seasons and the other for two. 
monthly reports for the muskratt catch per effective fur-taker vary from 22 to 33 , table 2. For the $1938-39$ and 1939 40 seasons, they are respectively 7 and 10 points lower than the figures for catch per effective fur-taker as derived from data collected by Brown; the average difference is about 9 points.

li similar correlations, or differences, between figures derived from the oral survey and the written monthly reports prevailed before the 1938-39 season, we may assume that in the seasons covered by this report, ending with 1939-40, approxi- mile for the 1938-39 and 1939-40 seasons is recorded in table 6 of the Brown \& Yeager report.

\section{MINK}

Distribution.-The distribution of the mink catch, fig. 6 , shows considerable irregularity. Several centers of abundance are apparent, one being in Lake County and another in Schuyler County. Generally, however, minks are moderately abundant in the northeastern quarter and the western half of Illinois. The largest

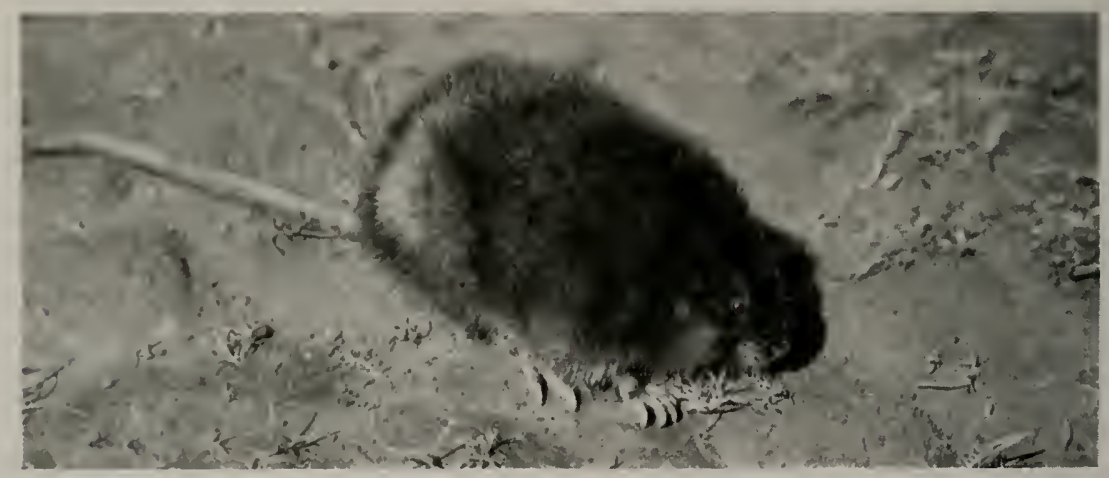

Fig. 5.-Muskrat caught in Champaign County. No furbearer occurs in greater numbers in Illinois than the muskrat. Nor do all of the state's other furbearers combined yield as great an annual cash return.

mately 18,375 fur-takers caught muskrats annually in the state. The annual catch of muskrats is calculated to have been $7+5,000$ during the $1929-30$ season and $88+, 395$ and $66+, 831$ during the 1938-39 and 1939-40 seasons, respectively; figures for the last two seasons are from table 6 of the Brown \& Yeager report. The average annual catch is estimated at about 653,000 muskrats. Income is estimated to have averaged around $\$ 500,000$ annually. Averages are for the seasons of this study ending with 1939-40.

'These averages indicate about 1 muskrat trapper to 3 square miles, or roughly 180 trappers per county; about 12 muskrats caught per square mile, or approximately 6,400 per county; and $\$ 9$ worth of muskrats caught per square mile, or about $\$+, 900$ worth per county. Figures are, of course, higher than the averages in more favorable regions and lower in the less favorable. 'These regions are indicated in fig. t. 'The average catch per square
Table 3.-Weighted per cent of Illinois furtakers who reported catching minks, and weighted average catch of minks per effective fur-taker; data derived from fur-takers' monthly reports, and weighting done on the basis of the relative size of the counties represented.

\begin{tabular}{|c|c|c|}
\hline SEASON & $\begin{array}{l}\text { Weighted } \\
\text { Per Cent } \\
\text { of } \\
\text { Fur-Takers } \\
\text { Catching } \\
\text { Minks }\end{array}$ & $\begin{array}{l}\text { Weighted } \\
\text { Average } \\
\text { Catch of } \\
\text { Minks Per } \\
\text { Effective } \\
\text { Fur-Taker }\end{array}$ \\
\hline $\begin{array}{l}1929-30 \ldots \\
1930-31 \ldots \\
1934-35 \ldots \\
1935-36 \ldots \\
1936-37 \ldots \\
1937-38 \ldots \\
1938-39 \ldots \\
1939-40 \ldots \\
1940-41 \ldots \\
1941-42 \ldots\end{array}$ & $\begin{array}{l}55 \\
62 \\
57 \\
58 \\
65 \\
50 \\
51 \\
51 \\
52 \\
43\end{array}$ & $\begin{array}{l}3.6 \\
3.3 \\
3.1 \\
3.4 \\
3.3 \\
2.9 \\
3.5 \\
3.4 \\
3.5 \\
2.8\end{array}$ \\
\hline
\end{tabular}


center of relative scarcity lies in the southeastern quarter of the state.

About nine times as many minks were caught in Lake County as in Mason County, in 1938-39 and 1939-40, accord-

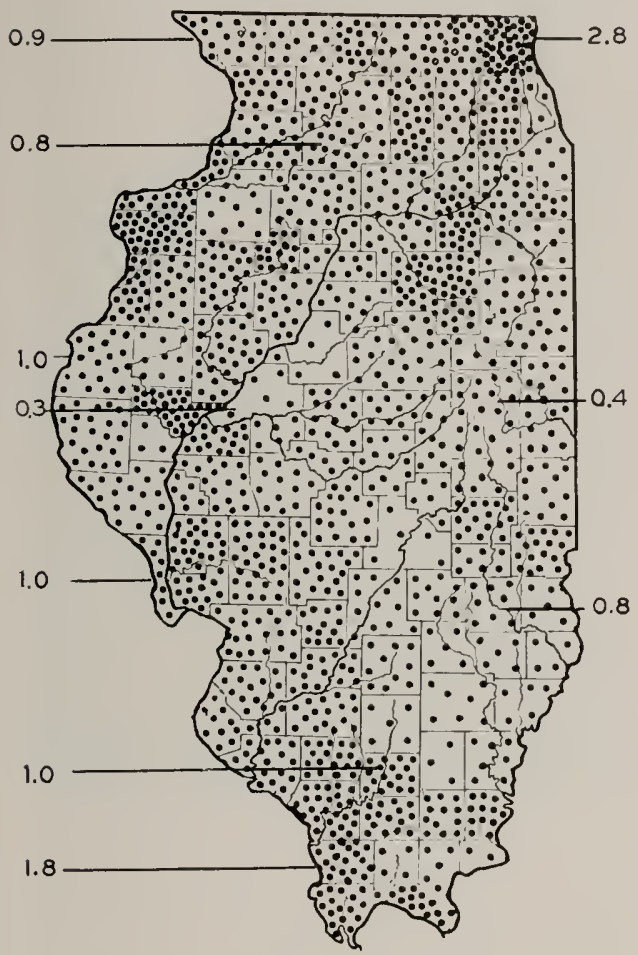

Fig. 6.-Distribution of minks in Illinois as indicated by fur-takers' monthly reports for the seasons of 1929-30,1930-31 and 1934-35 through 1939-40. Data for these eight seasons of monthly reports have been transferred to the map in such a way that the county having the largest average catch per fur-taker has the greatest density of dots; other counties are dotted proportionally. The numbers in the margins represent for each county indicated the average catch per square mile as revealed by Brown's survey for the 1938-39 and 1939-40 seasons. In general, a close correlation exists between the two sets of data, despite the fact that one is for eight seasons and the other for two.

ing to Brown's survey. It is probable that some of the counties in the southeastern quarter of the state had even fewer minks than did Mason County, fig. 6.

Trappers, Catch and Income.-The index figures for percentage of fur-takers catching minks, table 3 , vary from 65 and 62 during the 1936-37 and 1930-31 sea- sons, respectively, down to +3 in $19+1-42$, indicating a general population decline. The index figures are 5 and 6 points higher for the 1938-39 and 1939-40 seasons, respectively, than the percentages calculated on the basis of the oral survey data. Monthly report data show no change for the two seasons in the percentage of fur-takers catching minks, but oral report data indicate a rise in the second season.

The catch-per-effective-trapper index figures show no definite general trend for the 10 years for which we have data; the highest figure is 3.6 and the lowest 2.8 , table 3. Index figures are 1.0 and 0.3 point lower for the 1938-39 and 1939-40 seasons, respectively, than the average catch figures derived from data accumulated by the oral survey for these seasons. Monthly report and oral report data indicate a drop for the second season.

If these correlations, or differences, between the oral survey figures and monthly report indices held approximately constant back through 1929-30, then we may assume that about 12,400 fur-takers caught minks annually; the numbers were 15,600 and 17,800 during the 1929-30 and 193031 seasons, respectively, and $14,197 \mathrm{cal}$ culated for 1939-40 from data obtained and assembled by Brown. Also, we may assume, the total annual catch by these mink hunters and trappers was 72,000 and 87,000 during the 1929-30 and 193031 seasons, respectively, and $+5,25+$ for 1939-40, as recorded in table 11 of the Brown \& Yeager report, with an annual average of 56,000 . Income from minks is assumed to have averaged about $\$ 310$,000 annually. Averages are for the seasons of this study ending with 1939-40.

The above figures mean an average of about 1 mink trapper to each 4 square miles, or roughly 121 per county; about 1 mink caught per square mile, or roughly 560 per county; $\$ 5.50$ worth of minks per square mile, or $\$ 3,100$ per county.

A general decline in mink populations is indicated, the per cent of fur-takers who caught minks, and the number of successful mink trappers as well, having fallen noticeably in 10 years. The fact that the average-catch-per-effective-fur-taker indices show no consistent decrease suggests that the decline is due to actual disappearance of minks over wide areas rather than mere thinning of standing populations. 


\section{RACCOON}

Distribution.- The distribution of the coon ${ }^{*}$ population, fig. 7. in Illinois is much like that of the possum* population, fig. 10. Cons, fig. $S$, are least common in the prairie region centering around Livingston County and in an area in the south central part of the state. 'They are most common in the wooded counties hordering the Mis-

Table 4.-Weighted per cent of Illinois furtakers who reported catching coons, and weighted average catch of coons per effective fur-taker; data derived from fur-takers' monthly reports, and weighting done on the basis of the relative size of counties represented.

\begin{tabular}{|c|c|c|}
\hline SEASON & $\begin{array}{c}\text { Weighted } \\
\text { Per Cent } \\
\text { of } \\
\text { Fur-Takers } \\
\text { Catching } \\
\text { Coons }\end{array}$ & $\begin{array}{l}\text { Weighted } \\
\text { Average } \\
\text { Catch of } \\
\text { Coons Per } \\
\text { Effective } \\
\text { Fur-Taker }\end{array}$ \\
\hline $\begin{array}{l}1929-30 \\
1930-31 \ldots \\
1934-35 \\
1935-36 \\
1936-37 \\
1937-38 \\
1938-39 \\
1939-40 \\
1940-41 \\
1941-42 \ldots\end{array}$ & $\begin{array}{l}31 \\
28 \\
24 \\
29 \\
27 \\
32 \\
33 \\
35 \\
35 \\
37\end{array}$ & $\begin{array}{l}2.8 \\
2.7 \\
2.6 \\
2.3 \\
2.4 \\
2.8 \\
3.0 \\
2.8 \\
3.2 \\
3.0\end{array}$ \\
\hline
\end{tabular}

sissippi, Illinois, Ohio and Wabash rivers, particularly in those bordering the Mississippi and the Ohio in the southern end of the state.

According to figures from the oral survey, the yield in Calhoun County was 23 times as great, and in Union County it was $1+$ times as great, as in Champaign County.

Trappers, Catch and Income.Monthly report data indicate for the period of this study a decline of the coon catch (possibly ending about 1933), followed by a strong recovery, table $t$. For the 1938-39 and 1939-40 seasons, index figures for per cent of fur-takers catching coons, table $t$, are respectively 2 and 3 points lower than the corresponding figures calculated from information assem-

- Both popular aud literary usage sanctions use of the word comn for raccoon and possum for opossum. hled during the course of the oral survey. In both sets of data, the 1939-40 figures show a slight rise over those of the previous season. The average-catch-per-effective-fur-taker indices show a strong recovery after the 1936-37 season; the weighted figures varied from 2.3 during the 1935 36 season up to 3.2 during the $19+0-41$ season, table 4 . In both $1938-39$ and $1939-40$, they are 0.9 point below the average catch figures for corresponding years revealed by data accumulated for the Brown \& Yeager report. Both sets of data, therefore, show a slight decline for

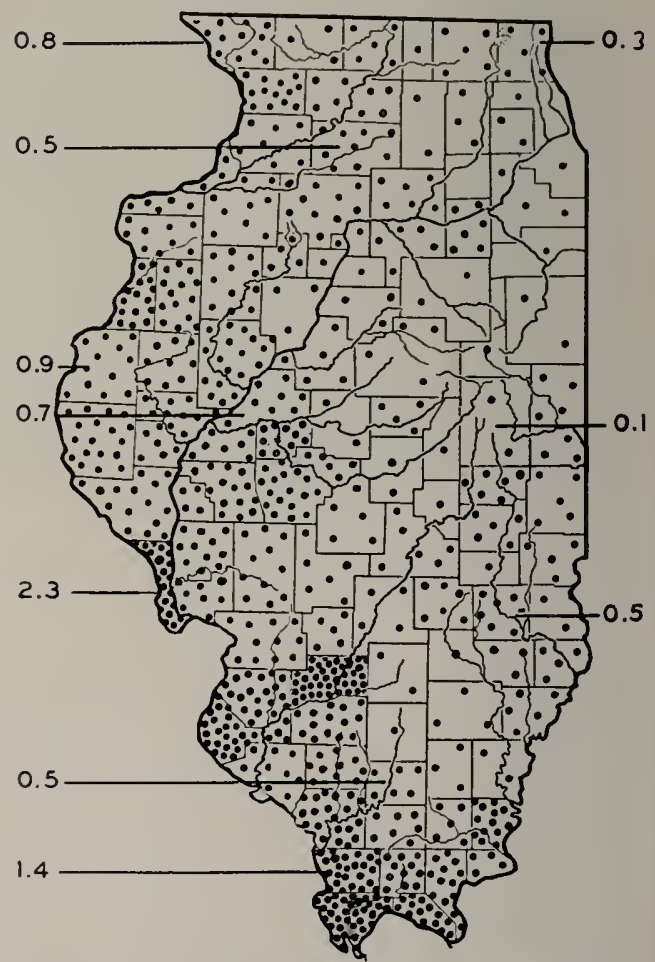

Fig. 7.-Distribution of coons in Illinois as indicated by fur-takers' monthly reports for the seasons of 1929-30,1930-31 and 1934-35 through 1939-40. Data from these eight seasons of monthly reports have been transferred to the map in such a way that the county having the largest average catch per furtaker has the greatest density of dots; other counties are dotted proportionally. The numbers in the margins represent for each county indicated the average catch per square mile as revealed by Brown's survey for the 193839 and 1939-40 seasons. In general, a close correlation exists between the two sets of data, despite the fact that one is for eight seasons and the other for two. 
the $1939-40$ season as compared with those of the previous season.

If these correlations, or differences, between monthly report index figures and corresponding figures derived from data accumulated in the course of the oral survey were constant previous to the 1938-39 season, then we may assume that an aver-

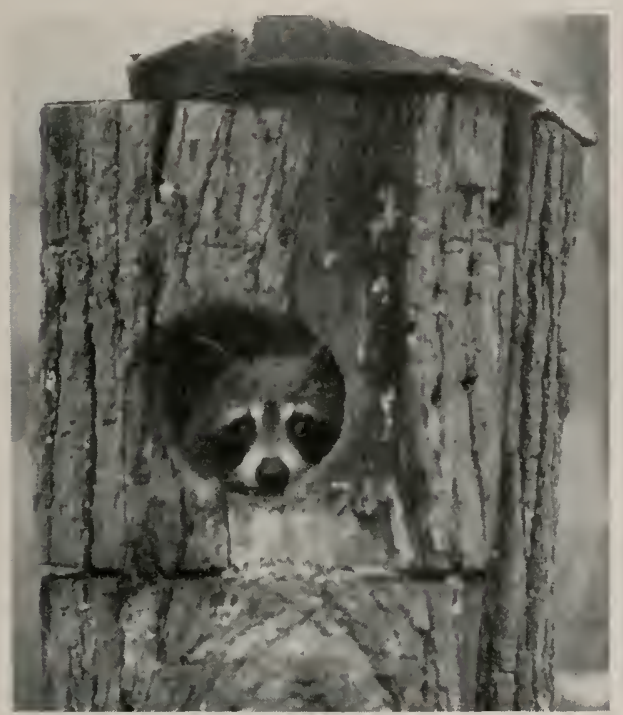

Fig. 8.-Female coon in slab box on the Chautauqua National Wildlife Refuge, Mason County. The box, originally erected for wood ducks, had been appropriated by the coon which, shortly before the picture was taken, had given birth to four young.

age of approximately 8,800 fur-takers caught coons annually; the calculated number was about 12,000 during the 1929 30 season and about 11,210 during the $1939-40$ season, 10 years later. As will be noted below, these figures are very conservative. The total annual catch of these coon trappers and hunters is estimated to have averaged at least 32,000 . Income is estimated to have averaged about $\$ 102$,000 annually. Averages are for the seasons of this study ending with 1939-40.

The above figures are equivalent to about 1 coon hunter or trapper per 6.4 square miles, or $\$ 6$ per county; 1 coon to 1.8 square miles, or $31+$ per county; about $\$ 1.80$ per square mile, or $\$ 1,000$ per county.

It is possible that the number of coon takers in 1929-30 may have been as high as 50,000 . It will be noted that, in the
1937-38 season, there was a large and suddenly increased percentage index of coon catchers from 27 to 32 , an increase of 5 points, table 4 . This 1937-38 figure was greater than that derived for any previous year, even 1929-30, and was due apparently to a change in the law, bringing a suddenly increased number of fur hunters to record, fig. 2. Fur hunters average a greater number of coons per individual than do trappers. Indications are that the 1936-37 data and those for all previous seasons should be raised 5 points to allow for inclusion of hunters not then recorded. Then the percentage of those fur-takers who caught coons in $1929-30$ would be up around 36 instead of 31 . This situation should be considered when examining the above calculations, which are based on the lower percentages. Probahly the total catch of coons declined more than our conservative figures show.

\section{SKUNK}

Distribution.- The average catch of skunks per fur-taker, converted into dots in such a way as to show the relative size of the catch in each county, indicates that the greatest skunk populations lie near our largest rivers, fig. 9. The counties along the Illinois River and the southern Illinois counties along the Mississippi stand

Table 5.-Weighted per cent of Illinois furtakers catching skunks, and weighted average catch of skunks per effective fur-taker; data derived from fur-takers' monthly reports, and weighting done on the basis of the relative size of the counties represented.

\begin{tabular}{|c|c|c|}
\hline SEASON & $\begin{array}{c}\text { Meighted } \\
\text { Per CENT } \\
\text { of } \\
\text { Fur-Takers } \\
\text { Catching } \\
\text { SKUnKS }\end{array}$ & $\begin{array}{c}\text { Weighted } \\
\text { Average } \\
\text { Catch of } \\
\text { Skunks Per } \\
\text { EFfective } \\
\text { Fur-Taker }\end{array}$ \\
\hline $\begin{array}{l}1929-30 \\
1930-31 \\
1934-35 \\
1935-36 \\
1936-37 \\
1937-38 \\
1938-39 \\
1939-40 \\
1940-41 \\
1941-42 .\end{array}$ & $\begin{array}{l}55 \\
59 \\
56 \\
45 \\
64 \\
49 \\
48 \\
48 \\
51 \\
44\end{array}$ & $\begin{array}{l}5.0 \\
5.9 \\
5.9 \\
4.7 \\
5.3 \\
3.7 \\
3.7 \\
3.7 \\
3.9 \\
3.1\end{array}$ \\
\hline
\end{tabular}


out as vielding most skunks. These are rolling and brushy. An area in the south central part of Illinois, another around

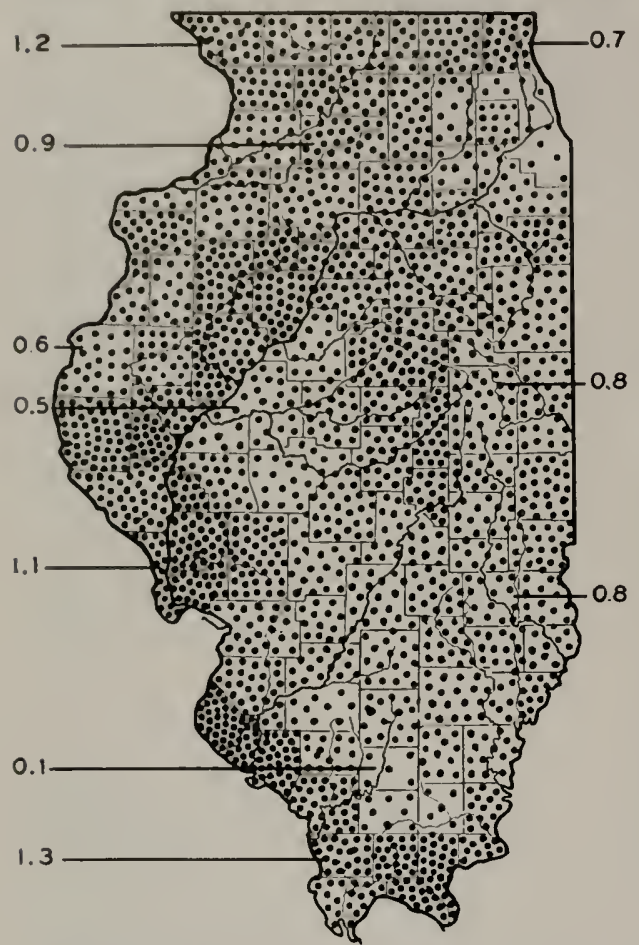

Fig. 9.-Distribution of skunks in Illinois as indicated by fur-takers' monthly reports for the seasons of 1929-30,1930-31 and 193t-35 through 1939-40. Data from these eight seasons of monthly reports have been transferred to the map in such a way that the county having the largest average catch per fur-taker has the greatest density of dots; other counties are dotted proportionally. The numbers in the margins represent for each county indicated the average catch per square mile as revealed by Browu's survey for the 1938-39 and 1939-40 seasons. In general, a close correlation exists between the two sets of data, despite the fact that one is for eight seasons and the other for two.

Springfield and a third around Cook County show yields of the smallest numbers.

Anong those counties that were surveyed by Brown, Franklin shows the smallest yield per square mile, and Union, Jo Daviess and Calhoun counties the largest. 'The rield in Union County was 13 times as large as the yield in Franklin County

Trappers, Catch and Income.-In- dex figures for per cent of fur-takers catching skunks show a general decline, table 5. The index figure is 55 for 1929 . 30 and $4+$ for 1941-42, but in intervening years figures as high as 59 and $6 t$ are recorded.

The average catch indices also decline; from 5.9 during the $193+-35$ season, the trend is downward, with some irregularities, to 3.1 during the $19+1-42$ season, table 5 .

For 1938-39 and 1939-40, index figures for per cent of fur-takers catching skunks are the same as, to 8 points higher than, corresponding figures calculated from data accumulated during the course of the oral survey. The average-catch-per-effectivefur-taker indices are from 0.1 to 0.5 point higher than the average catch per furtaker calculated from the oral survey data, the average difference being 0.3 .

If the differences and similarities between monthly report index figures and figures calculated from oral survey data obtain for years of this study previous to 1938-39, then we may assume that approximately 13,000 fur-takers caught skunks annually; the number is calculated to have been about 18,000 in $1930-31$ and about 12,000 during the 1938-39 season. The average annual catch of skunks was about 58,000 , having dropped from about 80,000 in $1929-30$ to a calculated 36,681 in 1939 40 , but with higher figures in some of the intervening years. The calculated average annual income from skunks was about $\$ 70,000$. Averages are for the seasons of this study ending with 1939-40.

These averages are equivalent to about 1 skunk hunter or trapper per 4.3 square miles, or roughly 130 per county; somewhat more than 1 skunk per square mile, or roughly 580 per county; about $\$ 700.00$ per county, or about $\$ 1.25$ per square mile.

\section{OPOSSUM}

Distribution.--In Illinois, possums are most common in the southern part of the state, particularly in those counties lying along the Mississippi and the Ohio rivers, as shown by the density of stippling in fig. 10 , which is based on monthly report data for the average bag per fur-taker. They are least common in the prairie region centering on Livingston County. 
Fig. 11 shows a possum from northern Illinois.

The oral survey indicates that the average catch per square mile in Calhoun County, one of the best, was 16 times as great as that in Champaign County.

Trappers, Catch and Income.-'The index figures for the percentage of furtakers catching possums show well-marked upward and downward trends that have the appearance of being cyclic, table 6 . The figures rise from $5+$ for the 1929-30 season to $7+$ for the $193+-35$ season, and then decline to 60 for the 1936-37 sea-

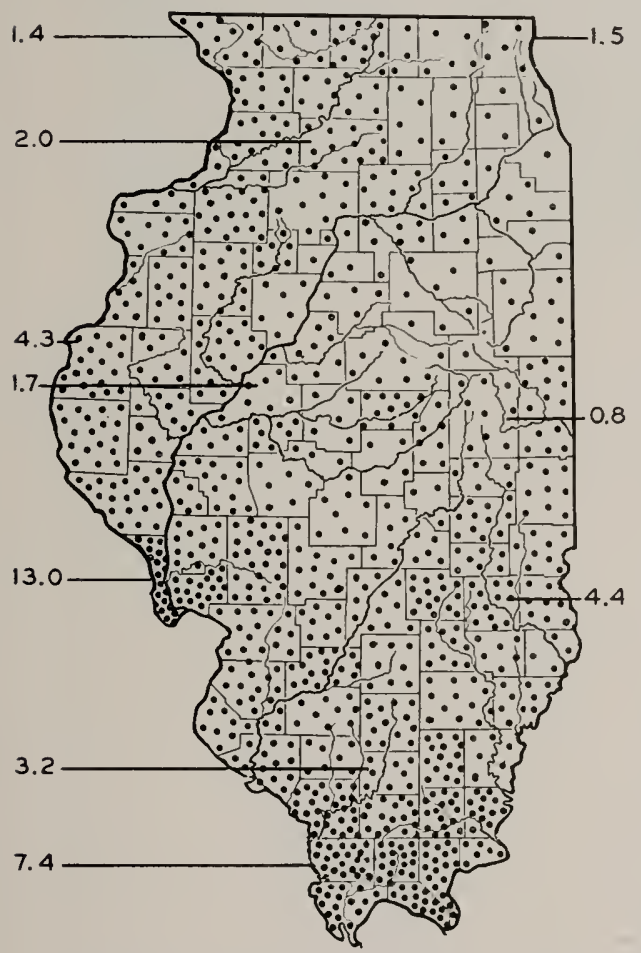

Fig. 10.-Distribution of possums in Illinois as indicated by fur-takers' monthly reports for the seasons of 1929-30,1930-31, and 193435 through 1939-40. Data from these eight seasons of monthly reports have been transferred to the map in such a way that the county having the largest average catch per fur-taker has the greatest density of dots; other counties are dotted proportionally. The numbers in the margins represent for each county indicated the average catch per square mile as revealed by Brown's survey for the 1938-39 and 1939-40 seasons. In general, a close correlation exists between the two sets of data, despite the fact that one is for eight seasons and the other for two.
Table 6.-Weighted per cent of Illinois furtakers catching possums, and weighted average catch of possums per effective fur-taker; data derived from fur-takers' monthly reports, and weighting done on the basis of the relative size of the counties represented.

\begin{tabular}{|c|c|c|}
\hline SEAson & $\begin{array}{c}\text { Weighted } \\
\text { P'er CENT } \\
\text { of } \\
\text { Fur-TAKers } \\
\text { Catching } \\
\text { Possums }\end{array}$ & $\begin{array}{l}\text { Weighted } \\
\text { Average } \\
\text { Catch of } \\
\text { Possums Per } \\
\text { Effective } \\
\text { Fur-Taker }\end{array}$ \\
\hline $\begin{array}{l}1929-30 \ldots \\
1930-31 \ldots \\
1934-35 \ldots \\
1935-36 \ldots \\
1936-37 \ldots \\
1937-38 \ldots \\
1938-39 \ldots \\
1939-40 \ldots \\
1940-41 \ldots \\
1941-42 \ldots\end{array}$ & $\begin{array}{l}54 \\
59 \\
74 \\
65 \\
60 \\
62 \\
65 \\
68 \\
66 \\
61\end{array}$ & $\begin{array}{l}5.0 \\
4.6 \\
6.2 \\
5.3 \\
4.6 \\
6.0 \\
8.0 \\
8.1 \\
6.9 \\
6.3\end{array}$ \\
\hline
\end{tabular}

son, only to rise again to 68 during the 1939-40 season; after that they again decline.

The trend of the weighted figures for average catch of possums per effective furtaker is similar and is cyclic in appearance, table 6 . They are highest for the 1938-39 and 1939-40 seasons.

Because data for the critical period bebetween the 1930-31 and 1934-35 seasons are not available, it is not possible to measure the distances between troughs and peaks in the cycle.

For the seasons of 1938-39 and 193940 , the monthly report index figures showing per cent of fur-takers who caught possums are respectively 1 and $t$ points higher than corresponding data derived from oral survey figures. For these same seasons, figures for the average catch of possums per effective fur-taker are respectively 3 points and 1 point lower than the catch per fur-taker averages calculated from data accumulated during the course of the oral survey:

If the same relationships between oral survey and written monthly report data held during previous years of this study', then we may assume that about 16,000 fur-takers caught possums annually; the number declined from about 20,000 during the 1929-30 season to 10,000 during the 1935-36 season and then rose to about 
18,000 during the 19.38-39 and 1939-40 seasons. These fur-takers are estimated (1) hase averaged about 1+1,000 possums anmually; most during the 1938-39 sea-
The questions to which the wardens replied had heen so worded that they may have been uncertain whether the information desired relative to foxes referred spe-

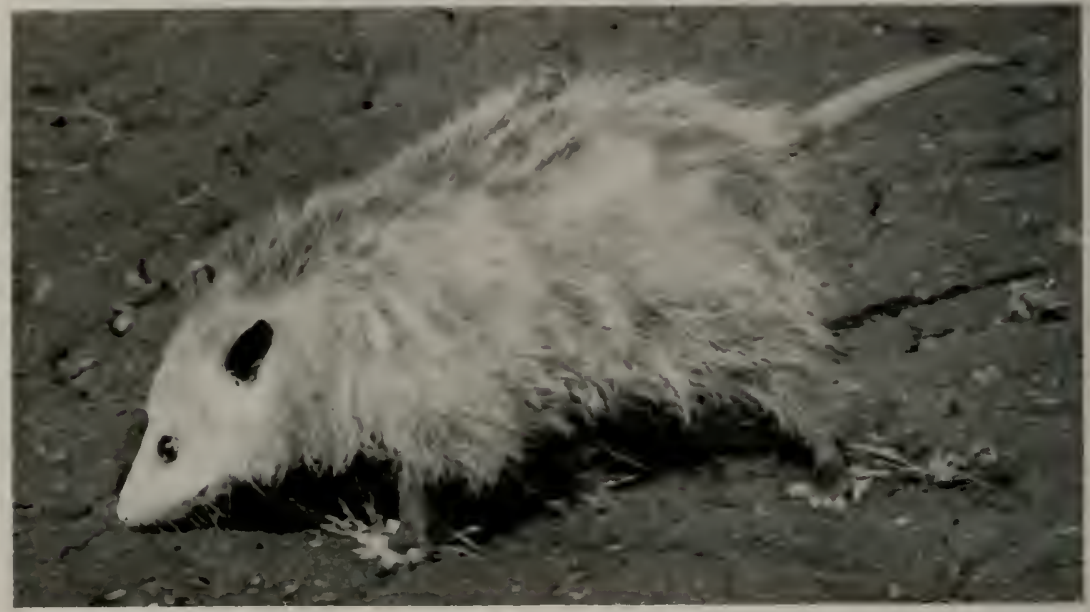

Fig. 11.-An immature possum caught in Cook County, $19+1$.

son, when the figure was about $2+t, 000$. The estinated annual income averaged about $\$ 39,000$. Averages are for the seasons of this study ending with 1939-t0.

'The above figures indicate about 1 possum hunter or trapper to 3.5 square miles, or roughly 160 per county; about 2.5 possums per square mile, or $1,+00$ per county; an income of about 70 cents per square mile, or roughly $\$ 390$ per county.

\section{FOXES}

Distribution.- The catch of foxes in Illinois, fig. 12, estimated from fur-takers' monthly report data, is decidedly greatest in the two southernmost tiers of counties. It is moderately large in the lower and upper counties bordering the Mississippi and along the Illinois and Embarrass rivers.

Red foxes are found in all lllinois counties, while gray foxes are found in comparatively few, fig. 13 . About 30 years ago, Forbes (1912) reported that foxes were found in +0 of the 102 counties of the state. A recent examination of ganne wardens' letters on which Forbes based his statements reveals that the wardens in more than half the counties of the state reported gray foxes, presumably the less widely distributed of the two species. cifically to their own counties or to the state as a whole. Most of them answered specifically for their respective counties. Some of the wardens of that day apparently were not aware that foxes occurred in the counties under their charge, and others perhaps did not know a gray fox from a red fox. Therefore, the accompanying map, fig. 13 , based in part on the reports from these wardens, may not give a highly accurate picture of the occurrence of gray foxes in Illinois in 1912.

Gray foxes were reported by wardens chiefly in the northern three tiers of counties, along the Illinois River, and along the Mississippi and Ohio rivers in the southern part of the state. Topographic features of these regions are favorable to gray foxes, and present records show that these animals occur there today; despite local inaccuracies, the general distribution pattern as derived by Forbes from the wardens' reports was probably approximately correct for 1912.

When timber was more widely distributed in Illinois than at present, the distribution of gray foxes in the state was possibly greater. "That condition may account for the reported occurrence of gray foxes in central Illinois in 1912.

Dates more recent than 1912 on the map, fig. 13 , refer to collecting or fur- 
takers' records. 'The fur-takers' records are believed to be highly accurate. They have been checked as to locality in which each reporting fur-taker operated. The determination in each case has every likelihood of being correct; the fact that each of these fur-takers, without being required by law to state whether he had caught a red fox or a gray fox, specified which kind he had caught indicates that he knew the difference.

It is of interest to note that those counties that bear recent date records for gray foxes, fig. 13, and are therefore in gray

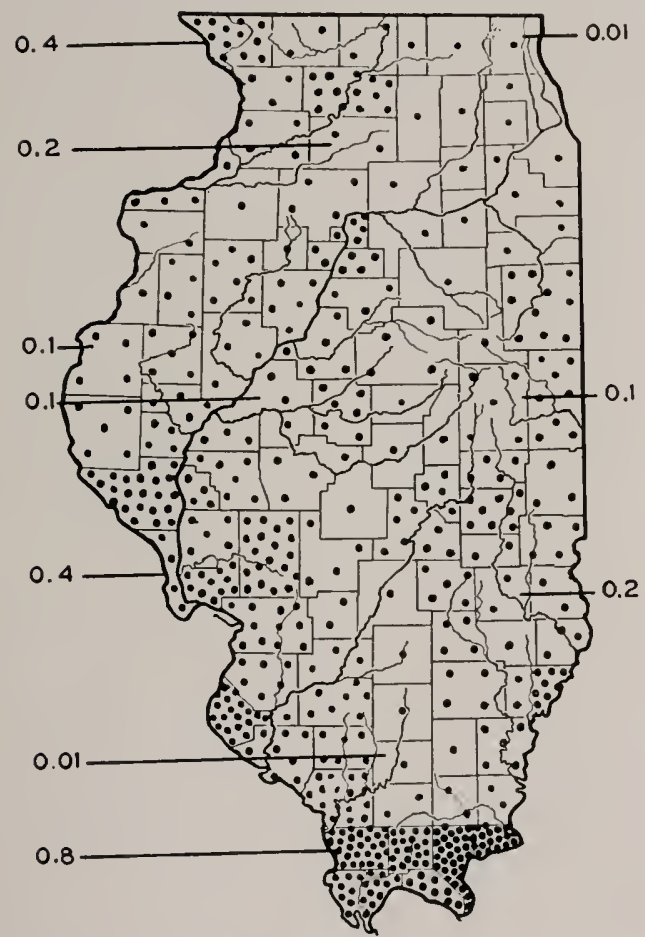

Fig. 12.-Distribution of foxes in Illinois as indicated by fur-takers' monthly reports for the seasons of 1929-30,1930-31 and 193+-35 through 1939-40. Data for these eight seasons of monthly reports have been transferred to the map in such a way that the county having the largest average catch per fur-taker has the greatest density of dots; other counties are dotted proportionally. The numbers in the margins represent for each county indicated the average catch per square mile as revealed by Brown's survey for the 1938-39 and 1939-40 seasons. In general, a close correlation exists between the two sets of data, despite the fact that one is for eight seasons and the other for two. fox range, show the highest concentration of foxes, both species combined, fig. 12. The gray fox population is largely responsible for the greater fox catches in these counties.

Trappers, Catch and Income.-Index figures for per cent of fur-takers catching foxes (red and gray) fluctuate with such regularity as to suggest cycles,

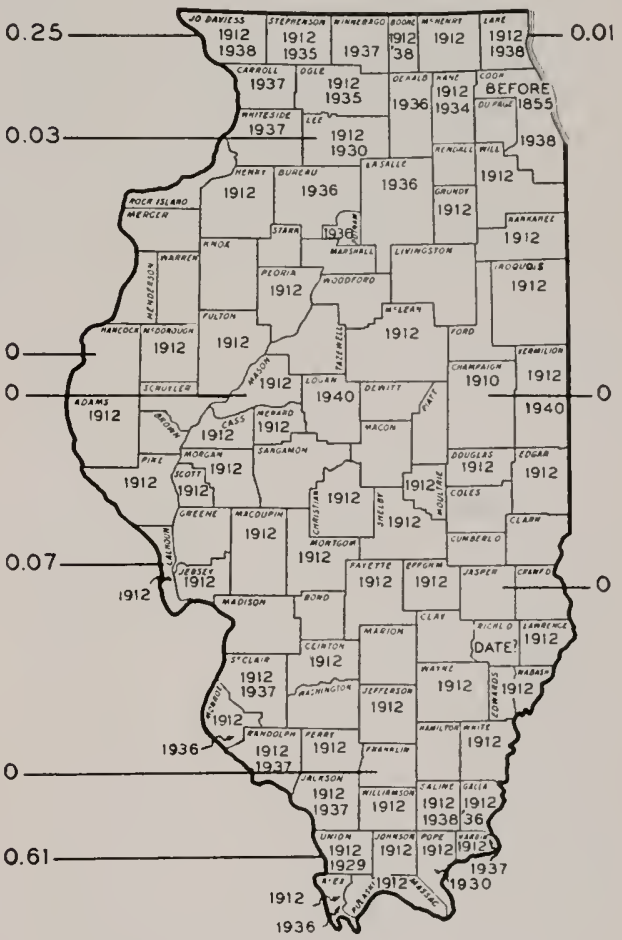

Fig. 13.-Recent specific records of gray fox occurrence in Illinois. Dates show counties in which gray foxes were reported for the year indicated. Figures in the margins show catch per square mile as revealed by the Brown \& Yeager report for the 1938-39 and 1939-40 seasons.

table 7. 'They rise from $1+$ for the 1934 35 season to 16 during the 1936-37 and 1937-38 seasons, and then drop to 14 during the $1938-39$ season, only to rise to 18 in $1940-41$.

The distance between peaks and troughs may not be measured because of lack of data for the three seasons following 1930 31.

The index figures for the average catch per effective fur-taker tend to run counter to the index figures for the per cent of 
fur-takers catching foxes, in general being high when the latter are low; but they show the same periodicity, nevertheless. This counter trend is of considerable interest hecause it is marked for foxes and because it is also characteristic of coons. Both animals are less common than some of the other furbearing species, and it may he that rises in numbers of foxes in 111 inois, possibly also coons, are more quickly reflected in index figures showing per cent of fur-takers catching the animal than in index figures showing the average catch

Table 7.-Weighted fer cent of Illinois furtakers catching foxes (red and gray), and weighted average catch of foxes per effective fur-taker; data obtained from fur-takers' monthly reports, and weighting done on the basis of the relative size of the counties represented.

\begin{tabular}{|c|c|c|}
\hline SEASON & $\begin{array}{c}\text { Weighted } \\
\text { Per Cent } \\
\text { of } \\
\text { ler-lakers } \\
\text { Catching } \\
\text { Foxes }\end{array}$ & $\begin{array}{c}\text { WEighted } \\
\text { Average } \\
\text { Catch of } \\
\text { Foxes Per } \\
\text { EFFEctive } \\
\text { Fur-Taker }\end{array}$ \\
\hline $\begin{array}{l}1929-30 \ldots \\
1930-31 \ldots \\
1934-35 \ldots \\
1935-36 \ldots \\
1936-37 \ldots \\
1937-38 \ldots \\
1938-39 \ldots \\
1939-40 \ldots \\
1940-41 \ldots \\
1941-42 \ldots\end{array}$ & $\begin{array}{l}12 \\
11 \\
14 \\
15 \\
16 \\
16 \\
14 \\
15 \\
18 \\
16\end{array}$ & $\begin{array}{l}2.1 \\
2.3 \\
2.5 \\
2.1 \\
2.2 \\
2.9 \\
2.9 \\
2.3 \\
2.5 \\
2.4\end{array}$ \\
\hline
\end{tabular}

per effective fur-taker; i.e., when foxes become common, many persons succeed in catching one fox each, whether they try or not, but their average is low because they do not repeat their success.

Index figures showing per cent of furtakers catching foxes are 0.0 to 2.0 points higher for 1938-39 and 1939-40, respectively, than corresponding figures calculated from data provided by the oral survey: Average catch indices for effective fur-takers are 1.3 and 1.1 points lower than the per fur-taker averages calculated from Brown's data for the 1938-39 and 1939-40 seasons, respectively.

If these differences between oral and written data held previous to the 193839 season, then we may assume that dur- ing the seasons of this study, ending with 1939-40, about 3,200 fur-takers caught foxes annually, totaling approximately 11 ,t00 foxes.

These figures amount to 1 fox trapper or hunter to about 18 square miles, or roughly 31 per county; and about 1 fox caught to each 5 square miles, or about 112 per county.

Numbers of Red Foxes Caught.It is not possible to estimate with great accuracy the annual income from foxes

Table 8.-Estimated numbers and values of red foxes caught in Illinois, by two-season periods; estimates based on fur-takers' monthly reports.

\begin{tabular}{r|r|r}
\hline \hline Seasons & $\begin{array}{c}\text { Estimated } \\
\text { Number }\end{array}$ & $\begin{array}{c}\text { Estimated } \\
\text { Value }\end{array}$ \\
\hline $1929-30$ and 1930-31 & 16,600 & $\$ 107,000$ \\
$1934-35$ and 1935-36 & 8,800 & 27,000 \\
$1936-37$ and 1937-38 & 17,000 & 52,000 \\
$1938-39$ and 1939-40 & 17,400 & 50,000 \\
Average per season & 7,500 & 30,000 \\
\hline
\end{tabular}

Table 9.-Estimated numbers and values of gray foxes caught in Illinois, by two-season periods; estimates based on fur-takers' monthly reports.

\begin{tabular}{c|c|c}
\hline \hline Seasons & $\begin{array}{c}\text { Estimated } \\
\text { Number }\end{array}$ & $\begin{array}{c}\text { Estimated } \\
\text { Value }\end{array}$ \\
\hline $1929-30$ and 1930-31 & 8,300 & $\$ 35,000$ \\
$1934-35$ and 1935-36 & 4,400 & 4,400 \\
$1936-37$ and 1937-38 & 8,500 & 12,900 \\
1938-39 and 1939-40 & 9,200 & 16,200 \\
Average per season & 3,800 & 8,600 \\
\hline
\end{tabular}

even by two-season periods earlier than 1938 because of the difference in value between pelts of gray foxes and red foxes and because the ratios of reds to grays change considerably from period to period.

According to the oral survey, 2.5 red foxes were caught for each gray fox during the 1938-39 season and only 1.4 reds to every gray during the next season. The ratio for the two seasons averaged about 2 reds to each gray. If this ratio held before the 1938-39 season, we may assume that the numbers of reds caught during the period of this study were about as shown in table 8 . We can be certain that the 


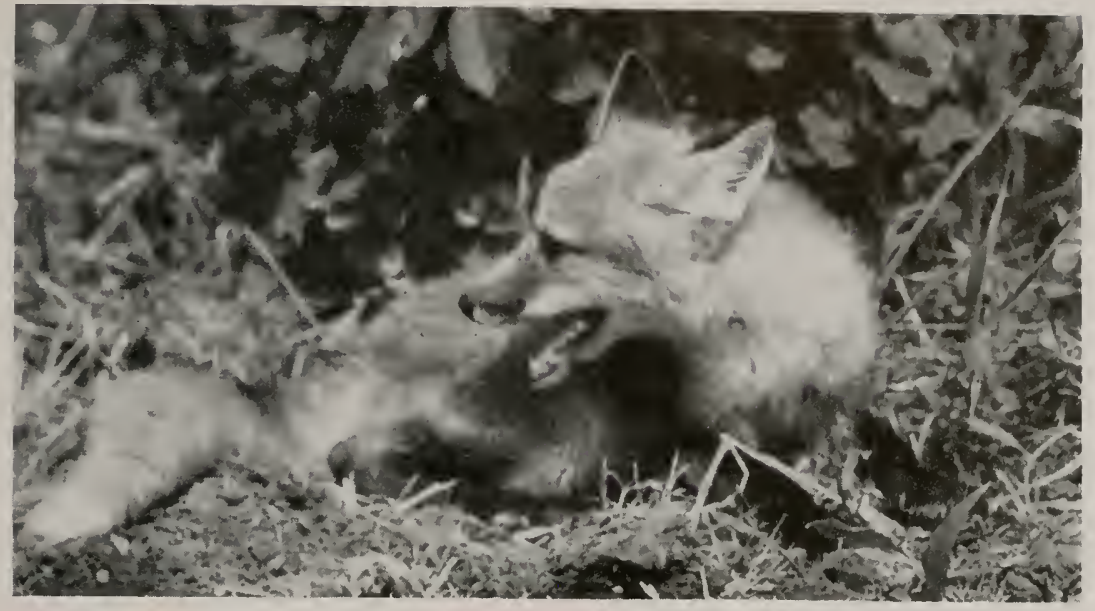

Fig. 14.-An immature red fox taken in Champaign County, $19+2$.

red fox catch outnumbered the gray fox catch by substantial numbers. Leopold (1931) indicates that, when he made a game surver of Illinois, many times more red foxes than gray were caught in Jo Daviess, Stephenson and Carroll counties, where gray foxes are relatively common. It is estimated that during the period of this study ending in 1939-40 about 7,500 red foxes were caught annually in Illinois, table 8 , roughly 75 per county, or an average of about 1 to each 7 or 8 square miles. An immature red fox is pictured in fig. 14 .

Income From Red Foxes.-The average annual income from red foxes for the period of this study ending in 1939t0 is estimated to have been about $\$ 30$,000 , table 8 ; or about 50 cents per square mile; roughly, $\$ 300$ per county. This annual income from red foxes is estimated to have averaged slightly more than $\$ 1$ per Illinois fur-taker.

Numbers of Gray Foxes Caught.The average annual catch of gray foxes for the period of this study ending with $1939-40$ is estimated to have been about 3,800 , table 9 ; or 1 to each $1+$ or 15 square miles. Most of the catch was concentrated in the hilly and timbered areas along the Mississippi and Ohio rivers. Gray foxes are now present in relatively few counties in Illinois; they were once more widely reported.

Income From Gray Foxes.-The average annual income from gray foxes for the period of this study ending with
$1939-40$ is estimated to have been $\$ 8,600$, table 9 ; or 15 cents per square mile.

\section{LONG-TAILED WEASEL}

Distribution. - The average annual catch of weasels per Illinois fur-taker, according to fur-takers' monthly reports, is greatest in an area extending from the northeastern corner of the state southwestward toward Knox County, fig. 15. Zones of moderate catches lie on either side of

Table 10.-Weighted per cent of Illinois fur-takers catching long-tailed weasels, and weighted average catch of these weasels per effective fur-taker; data obtained from furtakers' monthly reports, and weighting done on the basis of the relative size of the counties.

\begin{tabular}{|c|c|c|}
\hline SEAson & $\begin{array}{c}\text { Weighted } \\
\text { Per CEnt } \\
\text { of } \\
\text { Fur-Takers } \\
\text { Catching } \\
\text { WEasels }\end{array}$ & $\begin{array}{c}\text { Weighted } \\
\text { Average } \\
\text { Catch of } \\
\text { Weasels Per } \\
\text { EFfective } \\
\text { Fur-Taker }\end{array}$ \\
\hline $\begin{array}{l}1929-30 \ldots \\
1930-31 \ldots \\
1934-35 \ldots \\
1935-36 \ldots \\
1936-37 \ldots \\
1937-38 \ldots \\
1938-39 \ldots \\
1939-40 \ldots \\
1940-41 \ldots \\
1941-42 \ldots\end{array}$ & $\begin{array}{r}7 \\
7 \\
17 \\
13 \\
17 \\
12 \\
12 \\
15 \\
19 \\
9\end{array}$ & $\begin{array}{l}1.7 \\
1.8 \\
1.8 \\
1.6 \\
2.2 \\
1.5 \\
1.6 \\
1.9 \\
1.9 \\
1.3\end{array}$ \\
\hline
\end{tabular}


this strip of counties, one penetrating directly southward into the middle of the state. Another zone of moderately large

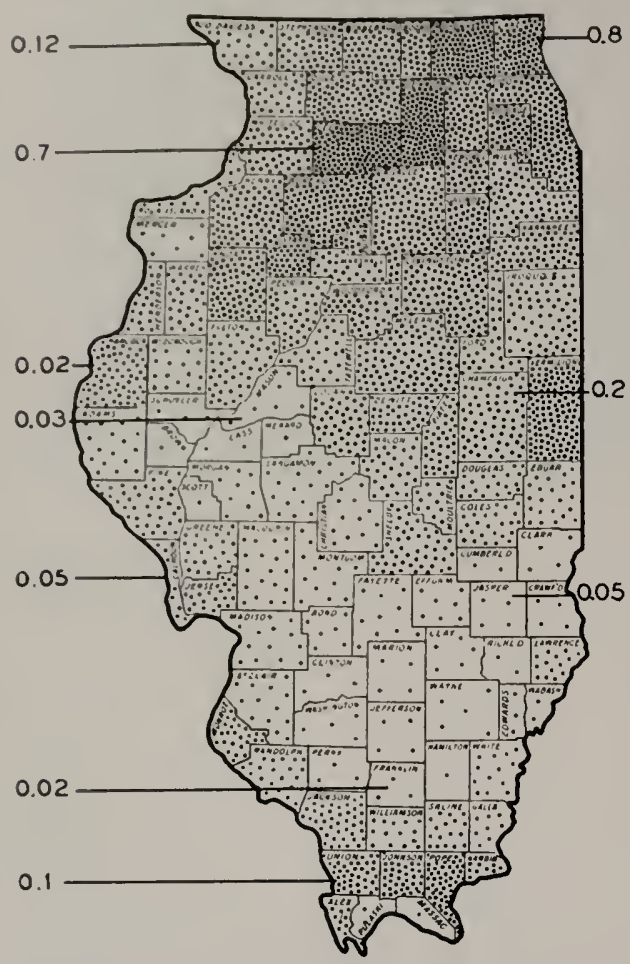

Fig. 15.-Distribution of long-tailed weasels in Illinois as indicated by fur-takers' monthly reports for the seasons of 1929-30, 1930-31 and 193+-35 through 1939-40. Data from these eight seasons of monthly reports have been transferred to the map in such a way that the county having the largest average catch per fur-taker has the greatest density of dots; other counties are dotted proportionally. The numbers in the margins represent for each county indicated the average catch per square mile as revealed by Brown's survey for the 1938-39 and 1939-40 seasons. In general, a close correlation exists between the two sets of data, despite the fact that one is for eight seasons and the other for two.

catches occurs in and near the second tier of counties in southern lllinois.

A zone of very small catches lies in the south central counties.

Winter white weasels have been reported 23 times from the northernmost tier of counties by trappers who filled out the fur-takers' monthly reports examined in the course of this study. From the second tier of counties they have been re- ported only 14 times, and from counties south of the second tier only + times.

Trappers, Catch and Income.-Index figures for per cent of fur-takers catching long-tailed weasels declined slowly following the 1934-35 season from 17 in that season and, after a high of 19 for the 19+0-41 season, reaching 9 in 19+142 , table 10 . The figure for the 1941-42 season is so little above the 7 for the $1929-30$ and $1930-31$ seasons as to indicate that the long-time population trend is probably not upward. Index figures for average catch per effective fur-taker follow a pattern somewhat similar to that of the figures for the per cent of furtakers catching weasels. Irregularities in the trend pattern appear due to and correlated with irregularities in reporting, with the possible exception of the figure for the 19+0-41 season, which may have marked a real peak.

Figures obtained from the written monthly reports for the per cent of furtakers catching long-tailed weasels are 3 to $f$ points higher than those obtained from data assembled by the oral survey. Both sets of data show an increase for the 1939-40 season over the preceding season.

The index figures for average catch per effective fur-taker for 1938-39 and 1939t0 are 1.6 points and 1.0 point lower, respectively, than fur-taker catch figures obtained from data assembled in the course of the oral survey.

If these differences and similarities held during previous years of the study, then we may assume that on an average about 2,200 fur-takers caught about 6,000 longtailed weasels annually, worth $\$ 1,500$. Averages are for the seasons of this study ending with 1939-40.

These figures amount to almost 22 weasel trappers per county, or 1 to each 26 square miles; 1 long-tailed weasel to each 9 or 10 square miles, or about 59 per county, averaging somewhat less than $\$ 15$ worth per county.

\section{LEAST WEASEL}

Although frequently caught, skinned and sold by inexperienced young trappers, least weasels are unimportant in the Illinois fur trade, being too small to interest furriers. They are commonly reported from Lake and McHenry counties, and, 
in 1939, the writer collected one of this very small species dead on the highway as far south as Henkel in the southeast corner of Lee County.

\section{BADGER}

Distribution. - Until badgers were given year-around protection, these animals were commonly caught by trappers in a group of counties in northern Illinois, most of them in the five counties in the northwestern part of the state that are heavily stippled on the distribution map, fig. 16. The number was usually between 5 and 15 annually in each of these counties. Moderate numbers were caught in those counties that are lightly stippled on the map, all of them close to the heavily

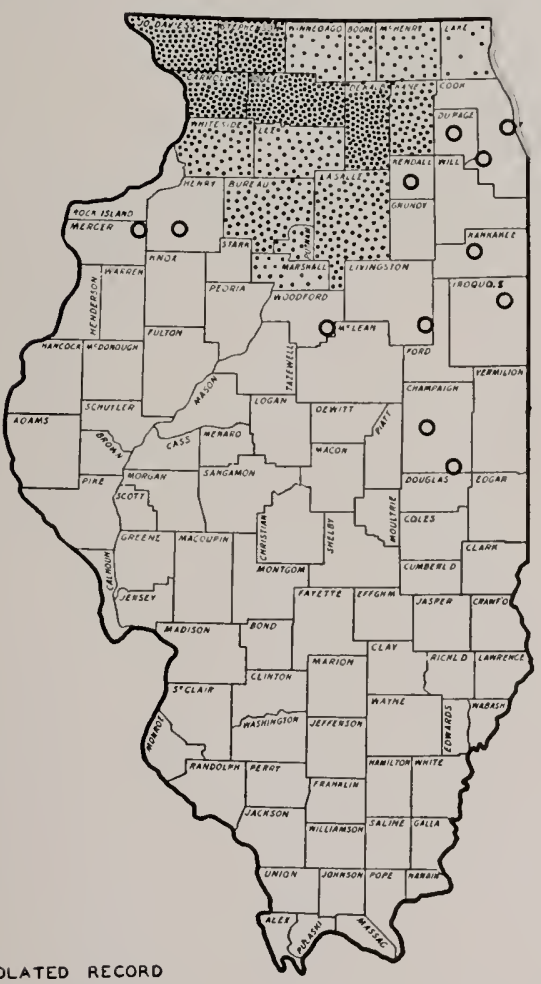

Fig. 16.-Distribution of badgers in Illinois as indicated by fur-takers' monthly reports for the seasons of 1929-30,1930-31 and 1934-35 through 1936-37. Data from these seasons of monthly reports have been transferred to the map in such a way that the county having the largest average catch per fur-taker has the greatest density of dots; other counties are dotted proportionally. stippled counties. The code in force July 1,1937 , placed badgers on the protected list with no open season. Since that date the legal killing of badgers has been limited to those animals destroying property.

Circles show localities from which badgers have been reported occasionally, fig. 16 . Most of these badgers were carried there as caged animals and finally liberated; others were pioneering far away from the main body of their present range. They do not occur regularly in the counties in which the circles are shown.

Kennicott (1855) stated that badgers were formerly common in Cook County and were, when he wrote, still common farther south. Later he added (1859) that in Illinois badgers were once numerous at least as far south as the middle of the state and were seen 30 years before near the Kaskaskia River. At that time they still existed in De Kalb County, according to him.

Brayton (1882) mentioned a badger taken in Kankakee County in 1857. Wood (1910) wrote that "reliable persons" reported they had seen a badger that had been killed a few miles north of Urbana in 1908.

Cory (1912) believed that, at the time he wrote, badgers still occurred "occasionally in the northern two-thirds of Illinois." Gregory (1936) recorded specimens from Du Page and Lake counties. Necker \& Hatfield (19+1) recorded an additional specimen from Lake County and one from near Chicago.

Joe B. Davidson, biologist of the U. S. Soil Conservation Service, reported a badger killed near Cambridge in Henry County in 1940 and added that badgers were becoming more common than they had been 4 years previously. One was caught in Mercer County, not far west of Cambridge, in 1929 , according to a note by a trapper.

A badger caught in the southeast corner of Woodford County a few summers ago was taken to the zoological park in Bloomington, only to escape within a few days.

Koestner $(19+1 a)$ reported a badger from Kankakee County in 1939; the skull of this animal is in his collection. During 19+2, residents of Martinton, Iroquois County, reported badgers fairly common there. Trappers reported to the writer that badgers were killed each year since 
1935 in Du Page, Kendall and Livingston counties. The writer saw a very old male with badly worn teeth caught in the southern part of Champaign County about 1930.

Extensive collecting and observation by biologists and game specialists of the Illinois Natural History Survey and by naturalists of the University of Illinois have shown that badgers are at present extremely rare as far south as Champaign County. For example, Koestner $(19+1 b)$ made no mention of having found any badgers while collecting in Ford County in 1940. In making his fur survey of Champaign County, Brown found no evidence to indicate that badgers had been killed in this county in 1938-39 or 1939$+0$.

Catch.-During the years for which we have data when badger trapping was legal, probably not over 150 and rarely over 50 badgers were caught annually in Illinois; the total number was not an appreciable percentage of the total catch of furbearers in the state. Their pelts being worth only about 75 cents each, badgers contributed little to the Illinois fur income.

Data are not sufficient to indicate much ahout changing numbers, but persons in the 1 llinois badger range commonly report that badgers are increasing. There is some indication that the range is being extended, counties around the outer margin of the range having shown a catch only in recent years.

\section{BOBCA T}

Once undoubtedly present throughout Illinois, the bobcat disappeared rapidly as the country was settled, partly because it requires extensive stands of unpastured timber and partly because it is exciting and easily treed game. Generally, it disappeared most rapidly in the northeastern and mideastern portions of the state. Kennicott (1855) reported it present sometime previous to 1855 in Cook County. A warden in Jo Daviess County reported to S. A. Forbes by letter that short-tailed wildcats disappeared from that county about 1850. Wood (1910) reported that early settlers declared wildcats were found in Champaign County between 1835 and 1840 . He obtained the skull of one of a pair killed in Alexander County in 1908.

Cory (1912) wrote, "It has lately been reported from Jo Daviess Co., Illinois, and Kennicott records it from Cook Co., although none has been observed in this vicinity for many years. There is a specimen in the Northwestern University collection at Evanston, taken near Rock Island, Illinois, some years ago. In extreme southern Illinois I have trustworthy information that it still occurs in more or less numbers in Galletin, Pope, Alexander, Jackson and Randolph Counties. Mr. J. G. Baker of Golconda, Pope Co., informs me that two Wild Cats were killed in that vicinity in the winter of 1907."

Forbes (1912), after making a statewide checkup on the condition of wildlife, stated that "lynxes and wildcats" were reported in 14 counties, 7 of them in extreme southern Illinois. Examination of the wardens' reports on which Forbes based his statement shows bobcats in 12

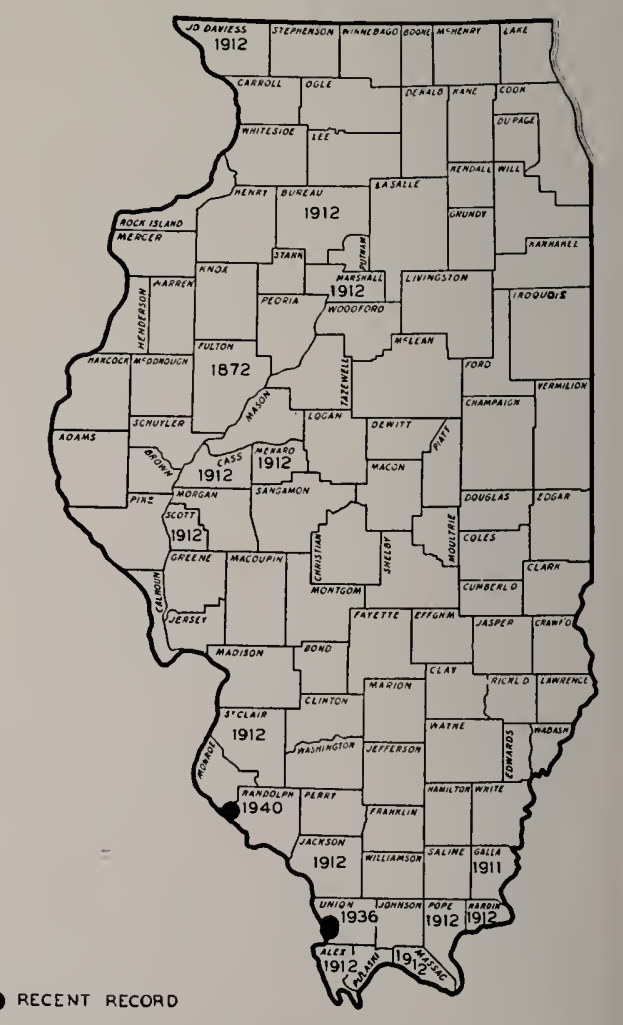

Fig. 17.-Recent specific records of bobcat in Illinois. Dates show counties in which bobcats were reported for the year indicated. 
counties, 7 of them bordering the Ohio or Mississippi rivers and 5 bordering the Illinois or Sangamon rivers, fig. 17.

Two bobcats were killed in Union County in 1936, and one specimen is mounted in a restaurant at Ware, fig. 18. One large bobcat was shot in a swamp near Miller City, Alexander County, in apiece, the pelts add little to the fur income of the state.

\section{OTTER}

Otters have long been so scarce in Illinois that they have not figured largely in the state's fur trade for many years.

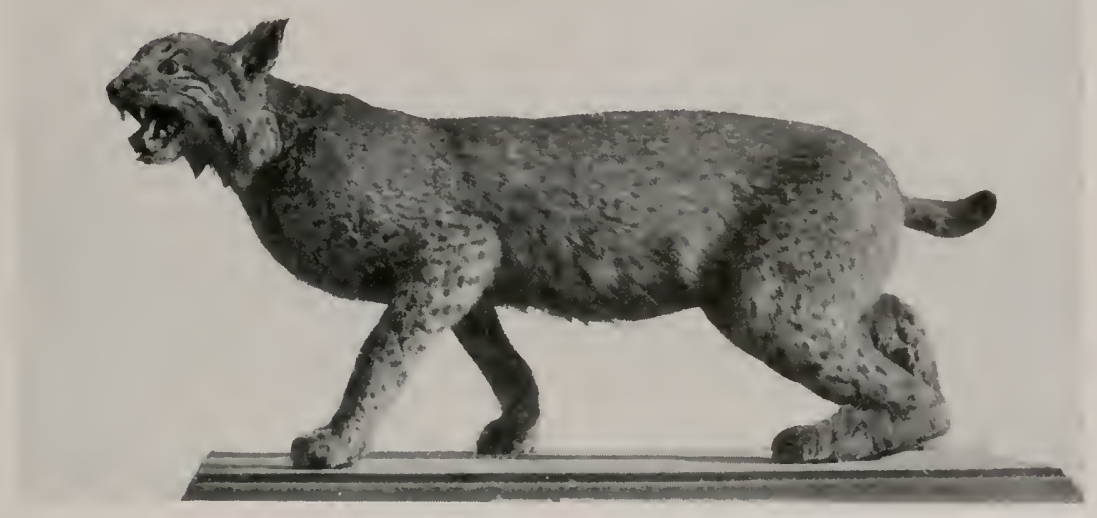

Fig. 18.-Bobcat or bay Jynx, Lynx rufus, caught at W'are, Union County, Illiuois, 1936. Its weight was 21 pounds.

November, 1942, one was killed near Murphysboro in December, 19+2, and three additional bobcats were killed, presumably near Murphysboro, late in $19+2$ or early in 19+3 (Anonymous 1943). An unverified recent record for Randolph County is reported by Necker \& Hatfield (1941). Earnest and excited hunters almost regularly report bobcats from various parts of the state, usually from the heavily wooded southern counties. The U. S. Forest Service $(1937,1938)$ fails to report bobcats within its Illinois holdings, the Shawnee National Forest, indicating that, if these animals are present, they are extremely rare. They are not now protected by law.

\section{DOMESTIC CAT}

In 5 recent years, 104 domestic cats were reported caught by the 8,862 furtakers making reports in those years. It is probable that the 121,566 trappers estimated to have operated during those years caught about 1,300 or more cats, or about 260 annually. Worth only about 10 cents
They were subject to an open season throughout lllinois until the end of the 1928-29 fur season. In the game code of 1929 , they were given complete protection until Nov. 15, 1933; before that date arrived, the period of complete protection had been extended indefinitely.

At one time distributed along all of the Illinois rivers, and, according to Kennicott (1855), not uncommon in Cook County about 1855, otters were by the winter of 1907-08 commonly reported only from southern Illinois; several were taken in the cypress swamps of Alexander County during that winter, according to Wood (1910). A few were still present in some of the counties farther north, bordering or near the Mississippi and Illinois rivers, fig. 19, according to Forbes (1912) who had requested Game Commissioner John Wheeler to obtain information about their distribution. Although the Commissioner so worded his letter to game wardens in each county that they might conclude that Forbes wished to know if otters were present anywhere in Illinois, most of them answered specifi- 
cally for their own counties and most of their answers showed close grouping near the Ohio, Wabash and Mississippi rivers in southern lllinois, where Forbes concluded otters were still common.

Since 1912, the record is one of rapidly receding range and, at least until the last half dozen years, of continuous failure to check their decline, even after legal protection was extended them throughout the vear.

According to an unpublished manuscript by Leopold (1929), an otter was taken near Meredosia, on the Illinois River, in 1926, and a few otters were present in Union County in 1929. Bennitt \& Nagel (1937) recorded two otters in $193+$ from the Mississippi River in Lincoln County, Mo., opposite Calhoun County, Ill., and

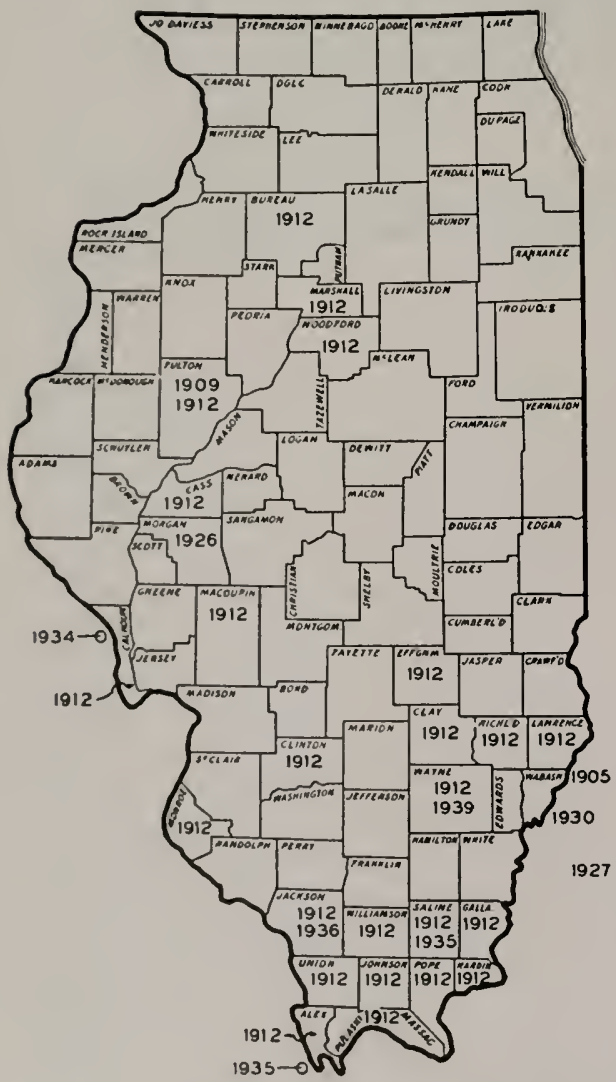

Fig. 19.-Recent specific records of otter in Illinois. Dates show counties in which otters were reported for the year indicated. Circles show nearby Missouri records. Dates east of Jlinois indicate nearby otter records in Indiana. others in 1935 in Missouri opposite Alexander County, Ill., fig. 19. Scott (1937) did not report any recent records on the Mississippi River in Iowa.

During the spring of 1939 an otter was accidentally caught in a fish net in the Little Wabash River in Wayne County by Harold Riggs of Goldengate, Ill. (Anonymous 1939).

According to a letter dated Jan. 26, 1939, from Galen IV. Pike of the U. S. Forest Service at Harrisburg, 11l., several otters were reported in Saline County, and an otter was seen in 1935 by William E. Bates at Big Lake, 2 miles northeast of Shawneetown, in Gallatin County. Residents of Union and Alexander counties still report otters occasionally, and it is hoped that the Shawnee National Forest in these southern counties, rising public interest and extended soil conservation practices will enable Illinois otters to survive and perhaps increase and spread. In recent estimates of the numbers of furbearing animals on the National Forests (U. S. Forest Service 1937, 1938), otters are not listed as being present in Illinois, probably because they are difficult to locate or extremely rare. Lyon (1936) found the general pattern of otter decline in Indiana similar to that in Illinois. Most of the recent dates for otter records in Indiana are in those counties bordering the Ohio and White rivers near Illinois; some of these dates are shown in fig. 19.

Bonnell (1941) reported 20 otters present in the Shawnee National Forest in southern Illinois in 1940. Some naturalists and rangers there are inclined to feel that this estimate is too large.

\section{COYOTE}

Wolves are often claimed to occur in Illinois; this common name is generally applied to coyotes, known also as brush wolves or prairie wolves, and sometimes to wild dogs. We have no reliable evidence that timber wolves are present within the boundaries of Illinois or that they have been during the present century, although Wood (1910) states: "During the years 1883 to 1905 inclusive, bounties were paid on 159 wolves killed in Champaign county. Wolves have been reported within the county since that date, and it is not at all unlikely that a few still exist 
in the heavy timber along the Sangamon River and the Vermilion."

Among about 1,600 fur-takers who reported during the 1939-40 season, only 2 stated that they had caught "wolves," which were probably coyotes. If the same ratio holds for the 25,000 or more trappers who did not report, we may assume that less than 40 coyotes were caught.

Coyotes are not protected by law at any time of year, and a number of them are annually turned in for bounty at a time when their pelts are not salable. Most are turned in for bounty in the northern half of Illinois; very few are taken in the southern quarter, fig. 20. Two skulls, turned in for bounty as those of "wolves,"

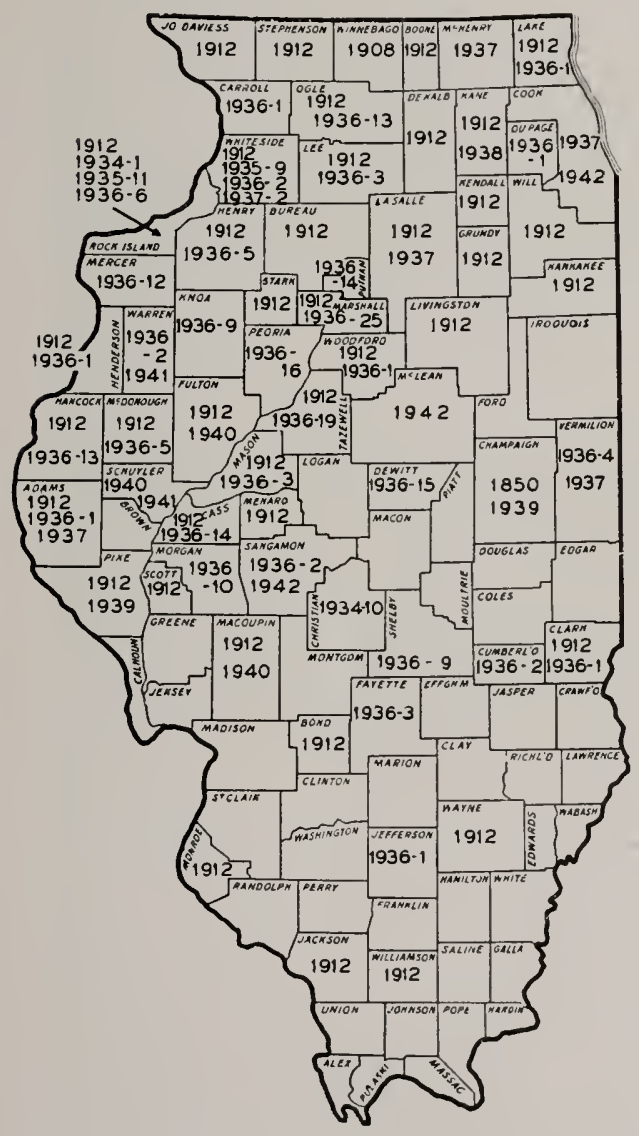

Fig. 20.-Recent specific records for Illinois of coyote and of dog misidentified as coyote or "wolf." Dates show counties in which these animals were reported for the year indicated. The numerals following some of the dates indicate the number of animals reported for those years. one in Schuyler County, figs. 21 and 23, and one in Warren County, figs. 22 and 23 , and now in the collection of $\mathrm{E}$. J. Koestner, formerly of the University of Illinois, were submitted to Dr. George G. Goodwin of the American Museum of Natural History, New York, who determined them as coyotes with possibly a faint trace of dog blood.

The Illinois Natural History Survey collection contains two skulls from McLean County and one from Sangamon County, collected in $19+2$ and determined as coyotes by E. A. Goldman of the U. S. Fish and Wildlife Service. A third, from the Cook County Forest Preserve District in $19+2$, has been determined as a coyote by the writer. Fig. $2+$ pictures the head of this animal.

A skull in the American Museum of Natural History, collected in Macoupin County in 1940, was determined as a coyote by Dr. Goodwin.

A rough idea of the distribution of coyotes in Illinois may be gained from reports of their presence in 1912, from the number reported turned in for bounty to county clerks and from reports in newspapers; however, some of the animals reported in newspapers as coyotes are wild dogs. Because dogs that run wild, as well as coyotes, are commonly reported by hunters, trappers, county clerks and reporters as "wolves," it is impossible to plot the distribution of these animals separately. Fig. 20 shows the distribution of so-called "wolves," coyotes and wild dogs reported as coyotes.

Some miscellaneous records are presented below.

Wood (1910) quotes early settlers as declaring coyotes were common in Champaign County about 1850 and seen in this county 10 years later.

During the 1937-38 season, trappers reported catching "wolves" at Payson, Adams County; Serena, La Salle County; and Bensenville, Cook County.

In about 1938, three hunters from Granville and Spring Valley captured two old "wolves" and seven cubs, according to the Illinois Sportsman for February, $19+0$; the location was probahly Putnam County.

During February, 1937, "wolves" were reported cornered in a gravel pit near Crystal Lake, McHenry County, accord- 


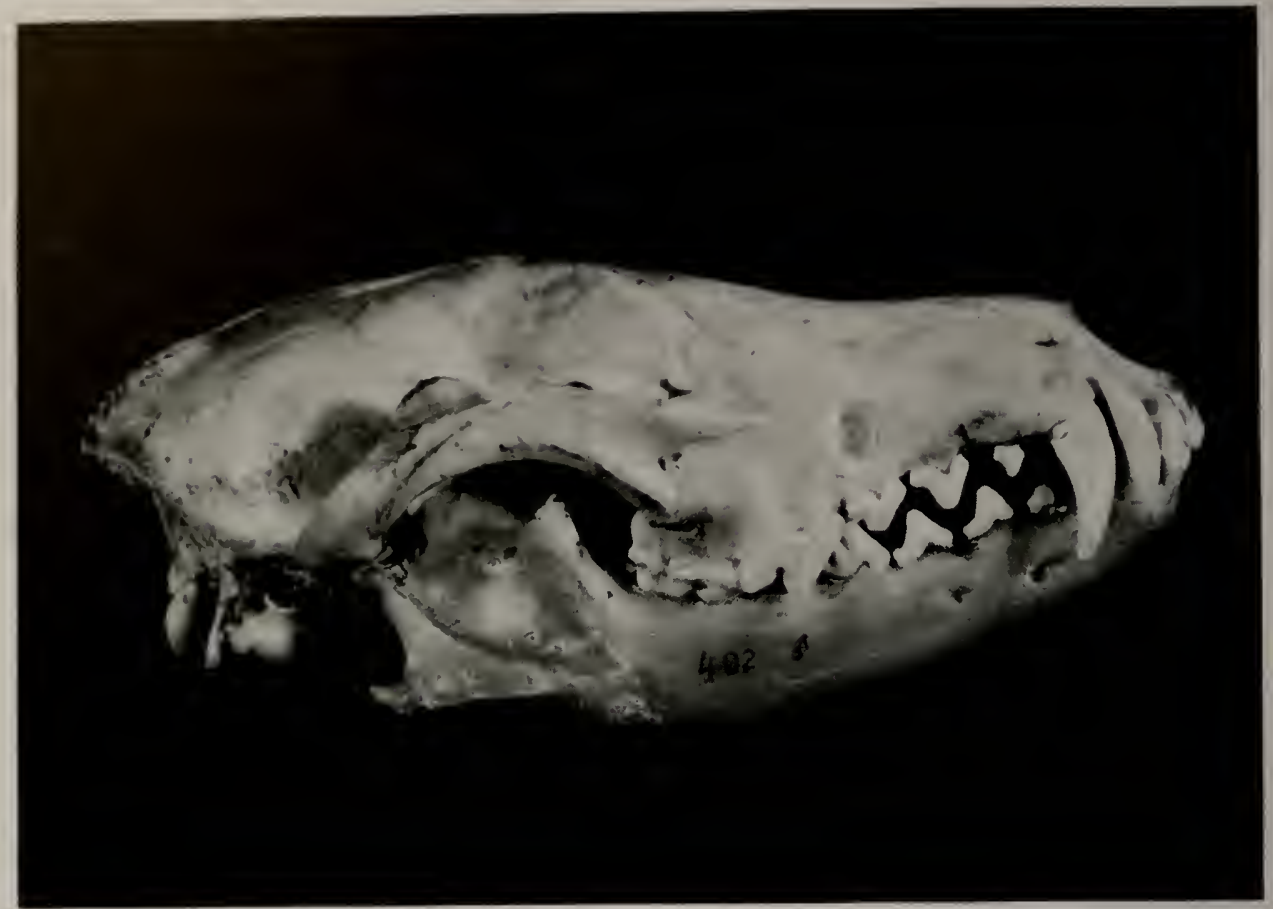

Fig. 21.-Skull of animal shot in Schuyler County, Illinois, January, 1941. Determined by Dr. George G. Goodwin as coyote with possibly a trace of dog.

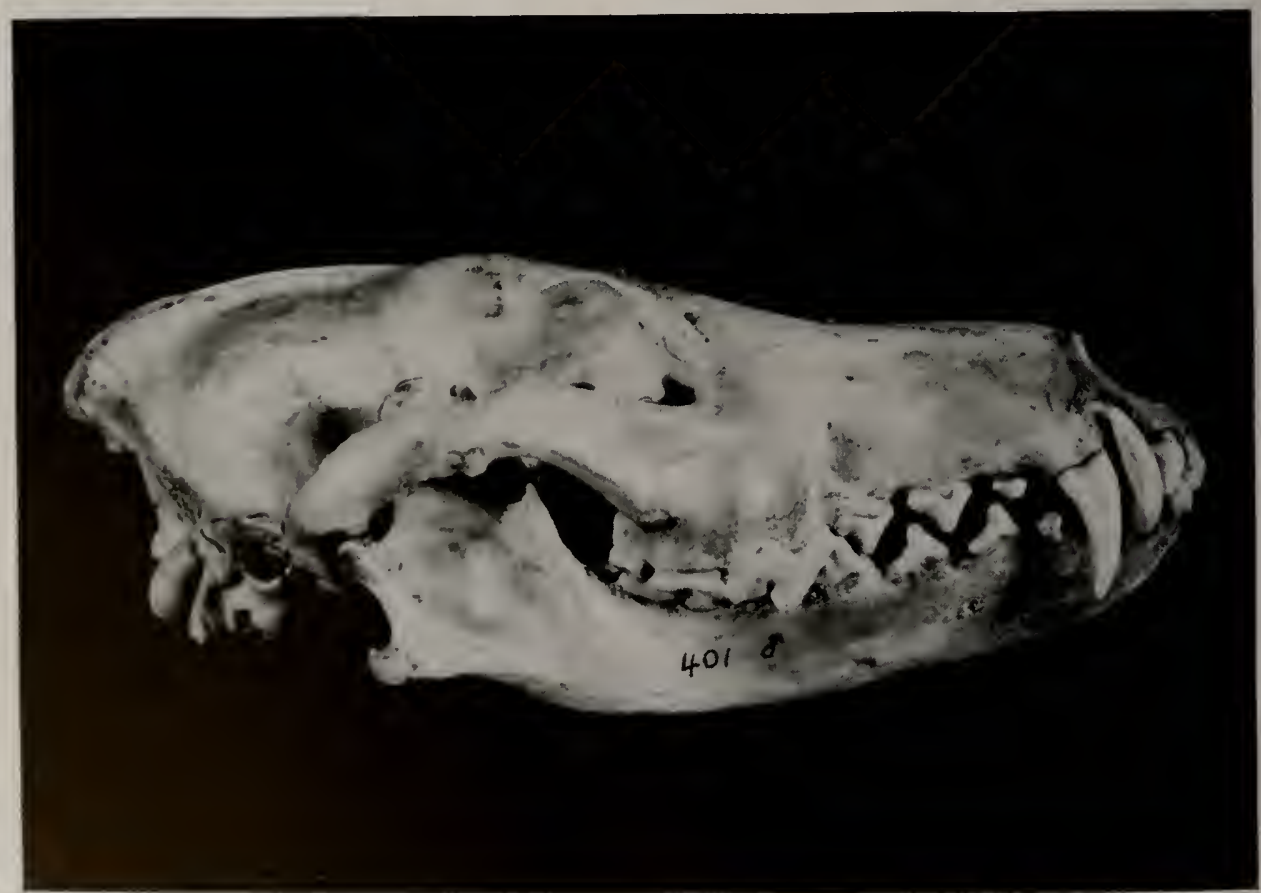

Fig. 22.-Skull of animal shot in Warren County, Illinois, January, 1941. Determined by Goodwin as coyote with possibly a trace of dog. 
ing to the Chicago Daily Tribune for Feb. 8, 1937.

About Jan. 7, 1937, the Danville Commercial-News carried a story about a "wolf" having been shot near Potomac, Vermilion County.

"Wolf" drives were planned or held April 5 and March 19, 1938, near Clinton, De Witt County, according to the Decatur Herald-Review for March 19, 1938.

A pack of "wolves" was found near Broadlands, Champaign County, about Feb. 16, 1939, according to the Arcola Record-Herald of that date. Two were shot on different days; one weighed 24 and the other 46 pounds, according to the newspaper account. The 24-pound individual was identified by the writer as a reddish chow dog, which in death, at least, carried its tail straight rather than curled in usual chow fashion.
According to the Chicago Daily Tribune of Dec. 28, 1938, a "wolf" weighing 33 pounds was shot the day before near Sugar Grove, Kane County.

In about 1938, wild dogs were common in rough country 4 miles north of Harrisburg, Saline County, according to R. E. Favreau, at one time employed by the Illinois Natural History Survey.

According to the Pike County Democrat, a "wolf" was shot near Summer Hill about Oct. 18, 1939, and another was seen. The county board had recently passed a resolution placing a bounty on wolves. One had been reported killed near Pittsfield a few weeks before the resolution was passed.

According to the Champaign-Urbana News-Gazette, Feb. 28, 1939, at least one "wolf" had recently been reported near Mahomet.

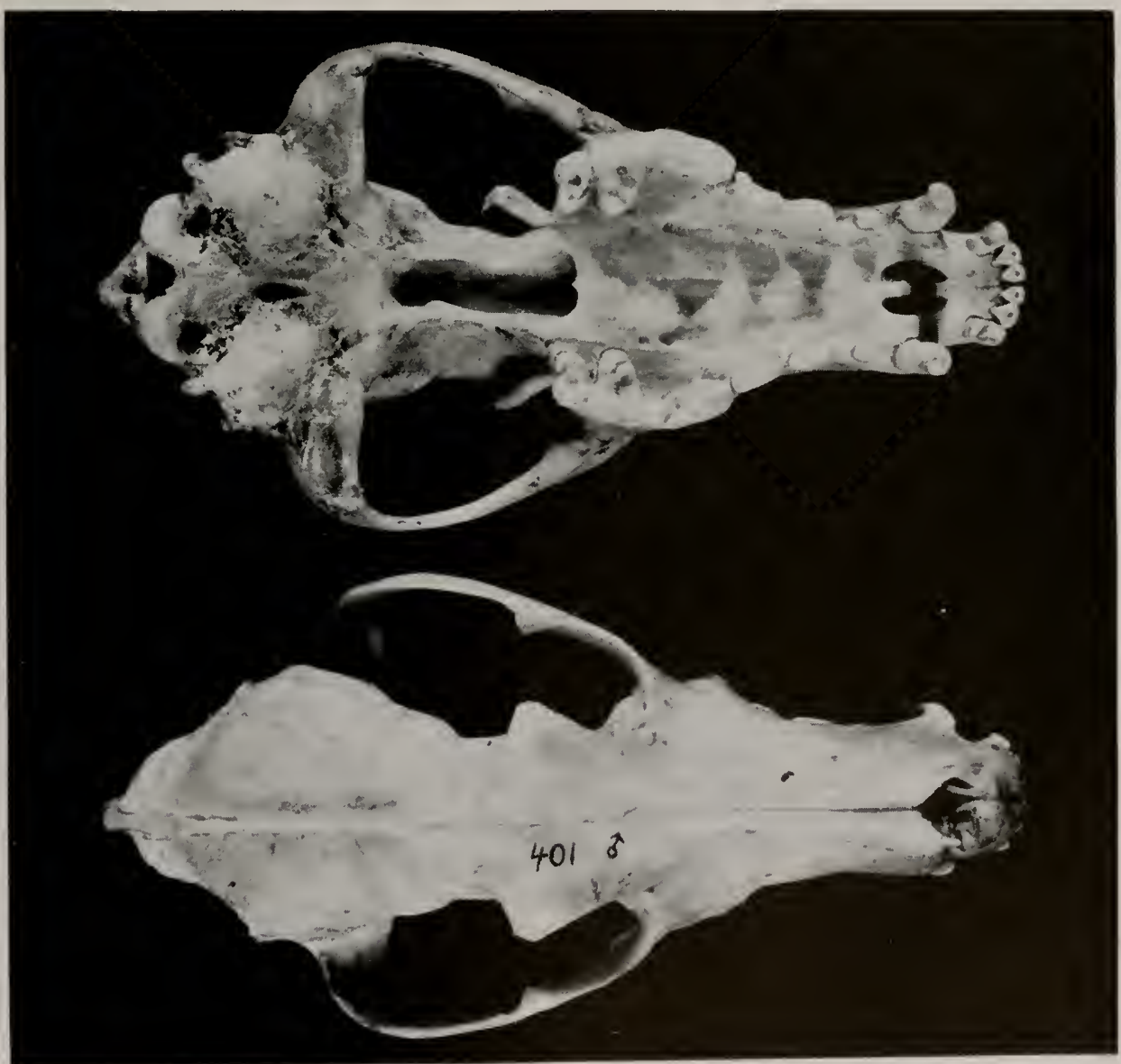

Fig. 23.-Another view of skulls of animals pictured in figs. 21 and 22. 
Alowt Dec. 6, 1936, a "wolf" and fox hunt was planned for near Morrison, Whiteside County. This vielded several graly foxe's and one red fox hut no coyote. much may be concluded from them: that coyotes, wolflike dogs or occasional coyotedog crosses are most commonly observed or captured in those counties lying along

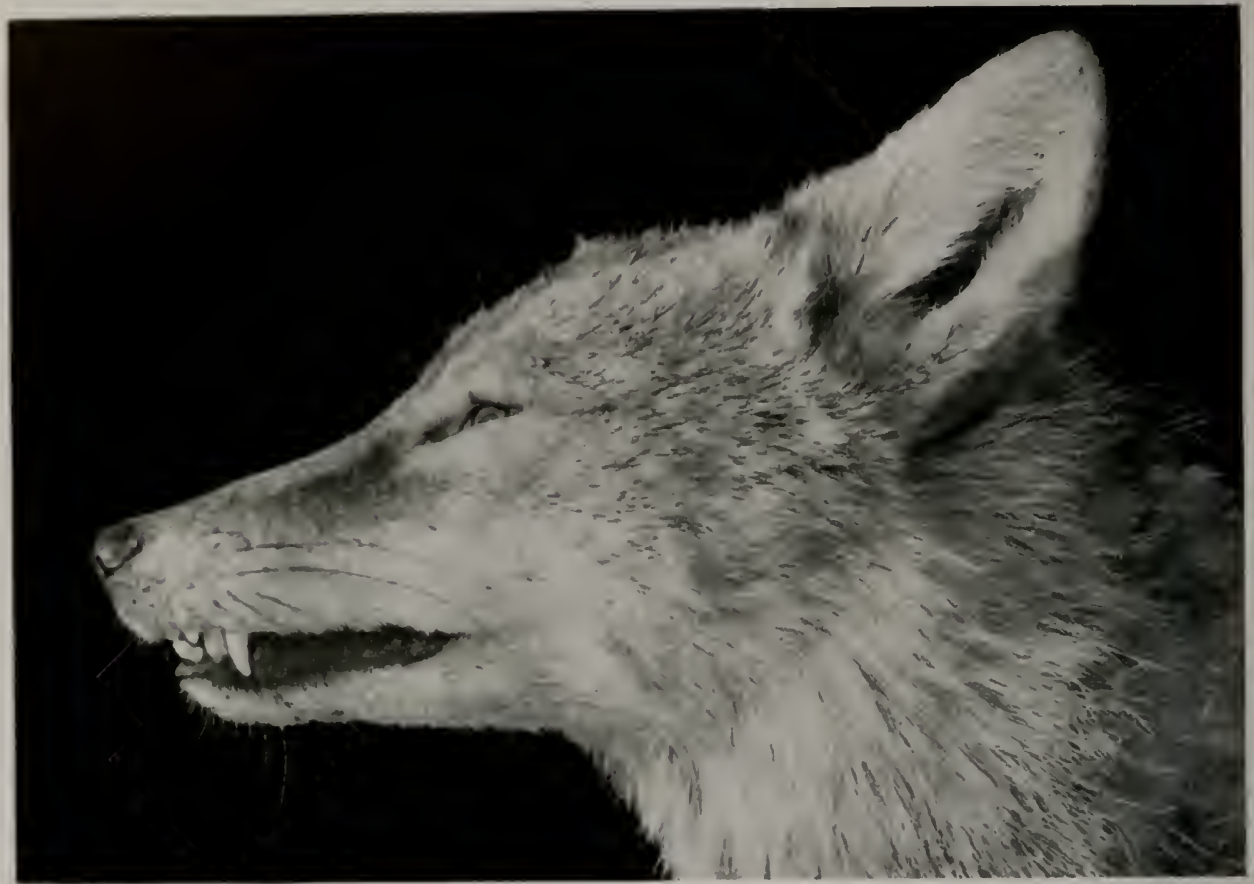

Fig. 24.-Head of coyote, Canis latrans, from Cook County Forest Preserve. Note length of tusks, shape of furred ears and streamlined skull.

Coyotes were common around Westfield, Clark County, in December, 1936, according to the Charleston Daily Courier, and some were shot. A man said to be familiar with coyotes in the western part of the United States thought that some of the animals shot were too heavy to be coyotes and claimed they were timher wolves.

In June, 1939, an animal killed in a roundup near Decatur was exhibited as a "wolf" at that city and the head was finally brought to the Illinois Natural History Survey; E. A. Goldman of the U. S. Biological Survey determined the skull as that of a dog.

Recently, Bonnell (19+1) reported 10 "Wolves and Coyotes" counted in one unit of the Shawnee National Forest in southern Illinois.

These miscellaneous records do not by any means come near to exhausting the list of references on the subject. This the Des Plaines River, the lllinois River and the Mississippi River in the northern part of the state.

\section{MARTEN}

Martens have by pure accident been recorded recently from Illinois (U. S. Forest Service 1937). The Illinois game code for some of the years previous to 1941 listed martens among the protected furbearing animals, and various journals copying Illinois fur laws assumed martens to be present in the state. 'The marten has probably been extinct in Illinois beyond the memory of men now living.

\section{SPOTTED SKUNK}

Cory (1912) lists and maps spotted skunks or civets as present in southern Illinois, basing his judgment partly on a statement by another writer that they 
were reported to be fairly common at Golconda. No reliable evidence has turned up since to show that spotted skunks are present anywhere in this state, although the F. C. 'Taylor Fur Company of St. Louis, Mo., lists prices of Illinois civets.

\section{BEAVER}

Although beavers once occurred throughout Illinois, Wood (1910) wrote that they seemed to have been practically exterminated in and around Champaign County before the first permanent settlers came. Forbes (1912) wrote that beavers were reported in four Ohio River counties. They later became extinct in Illinois, but have since been reintroduced, fig. 25 .

The first shipment of reintroduced beavers was released Nor. 2, 1935; 10 in Hunting Branch, a tributary of Bay Creek, 6 miles southeast of Stonefort, and

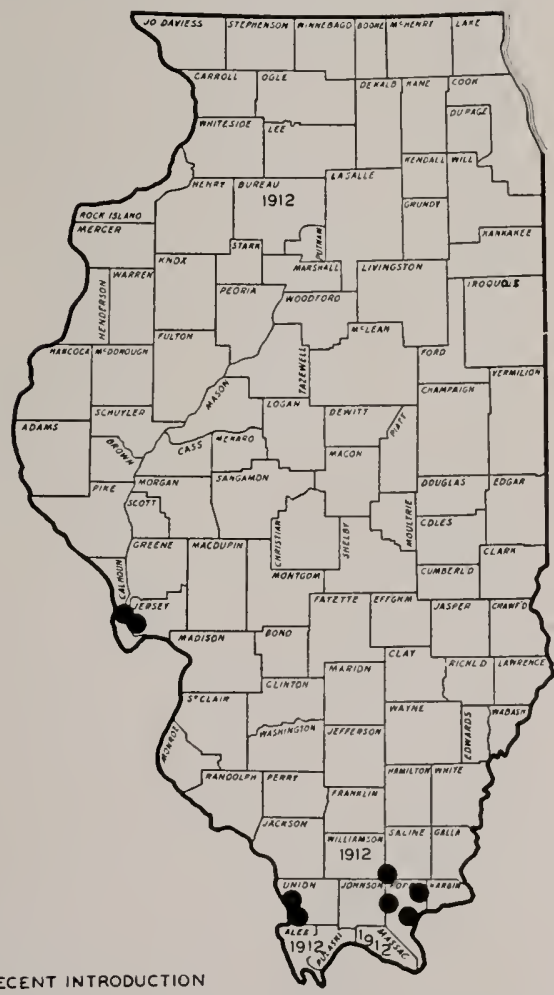

Fig. 25.-Records of beaver occurrence in Illinois. Dates show counties from which they were last recorded. Large dots indicate recent introductions of beavers into Illinois.
9 in Grand Pierre Creek, 2 miles southeast of Herod, both locations in Pope County. Soon afterwards, those in Hunting Branch moved downstream into Bay Creek, where their signs were observed over $11 / 2$ miles south of the place at which they were released. A year later some of these were found in the locality of the town of Robbs, which is about 8 miles from the spot of release. 'Those liberated in Grand Pierre Creek remained in the general locality, where they built one dam and where their cuttings and other signs are now common.

During the fall of 1938, three beaver dams were reported in Lusk Creek about 5 miles up from its mouth at the Ohio River. In order to find their way here, the beavers probably migrated down Bay Creek to the Ohio River, then up the Ohio to Lusk Creek, and finally up Lusk Creek 5 miles to the new location. It is not likely that they traveled across country between Bay Creek and Lusk Creek.

On March 1, 1936, four beavers were received from $W$ isconsin. One died enroute and a second, weakened or injured by the trip, died shortly after it was set free. The skull of this second animal is in the Illinois Natural History Survey collection. The live animals were turned loose on the property of the East St. Louis Hunting Club near Reynoldsville, in Union County. No beaver or beaver signs were reported there until late in 1938, when a dam was found across Clear Creek Drainage Ditch, west of the hunting club. In 1940, there was a large used beaver burrow near this club and a lodge near Reynoldsville. A Union County beaver lodge is shown in fig. 29 of the Brown \& Yeager report.

A small colony was recently reported present at a lake owned by L. E. Groppel, Rosedale Township, Jersey County; beavers were introduced there by the State Department of Conservation in August, 1936 (Thatcher 1937).

The last consignment of beavers consisted of three received during October, 1938. These animals were released in La Rue Swanp, 2 miles north of Wolf Lake in Union County, the most favorable of the sites where heavers have been released.

The beavers (a total of $2 t$ in addition 
to the Groppel Lake colony) released in southern Illinois have firmly entrenched themselves there. The total estimated population in the Shawnee National Forest in 1939 was 48 . 'They numbered only 19 in December, 1935, and 25 in 1937, according to U.S. National Forest estimates of furbearing animals in national forests. Bonnell (1941) reported "about $70^{\prime \prime}$ heavers present in the Shawnee $\mathrm{Na}$ tional Forest by 1940. They are now widely scattered and should continue to increase.

\section{TOTAL ANNUAL GATCH}

Probably about 958,000 individuals of our eight common furbearers are caught annually in Illinois, or 17 per square

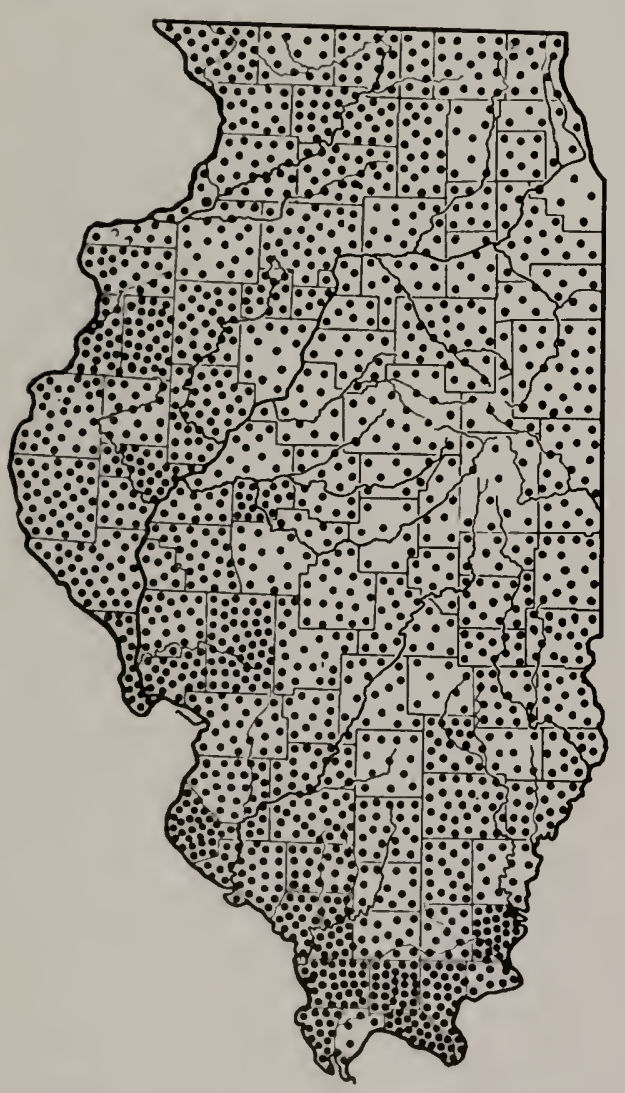

\section{Distribution of Predator catch.}

Fig. 26.-Distribution of predatory species iu Illinois as indicated by fur-takers' monthly reports for the seasons of 1929-30, 1930-31 and 1934-35 through 1939-40. mile, amounting roughly to 9,400 per county. Individual fur-takers average about 37 animals each per year.

Most of the predatory and omnivorous species are caught in the southern, southwestern and western counties, fig. 26, where extensive woods or bushy areas make favorable habitats for them. Most

Table 11.-Estimated average annual number of common furbearers caught in Illinois beginning with the 1929-30 season and ending with the 1939.40 season $(1931-32,1932-33$ and 1933-34 omitted because data for these seasons were not available).

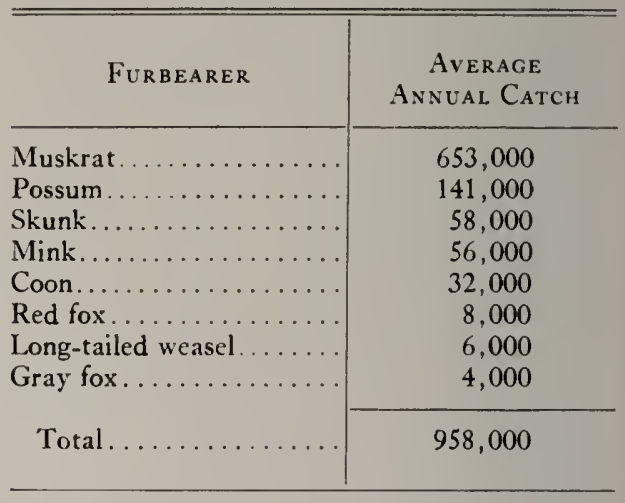

of the muskrats, the state's single legally caught herbivorous furbearer, are taken in the northern counties, fig. $t$.

The total number of furbearers caught, so far as we are able to estimate from data collected, was about as great during the 1938-39 and 1939-40 seasons, covered by the oral survey, as during any other recent 2 -year period; although there was a decline in the total numbers of minks and coons caught in the seasons in which Brown made his survey, an unusually large number of muskrats and an increased number of long-tailed weasels and foxes were caught in those seasons.

About 68 per cent of the common furbearers caught in Illinois during the period beginning with the $1929-30$ season and ending with the 1939-40 season were muskrats, table 11 (the seasons of 1931$32,1932-33$ and 1933-34 are omitted from the calculations because data for them were not available). Possums held second place, making up about 15 per cent of all furbearers caught.

During some seasons more minks than skunks were caught, but over the period 
of this study the total number of skunks caught slightly exceeded the total number of minks. Each species constituted about 6 per cent of the total catch. Coons made up about 3 per cent of the catch.

Red foxes and gray foxes were caught in small numbers, together making up somewhat less than 2 per cent of the catch. Long-tailed weasels made up less than 1 per cent of the catch.

Muskrats were the most numerous furbearers in all but a very few counties, where they were exceeded only by possums. In those counties in which muskrats did not lead, they were in second place for numbers in the catch.

\section{TOTAL ANNUAL INGOME}

The average annual income from the Illinois fur catch for the period beginning with the 1929-30 season and ending with the 1939-40 season (seasons of 1931-32, 1932-33 and 1933-34 omitted for reasons explained above) amounted to about $\$ 1$,067,500 , table 12 , or about $\$ 19$ per square mile. These figures are based upon prices for No. 1 medium rather than No. 1 large pelts, table 13. The income was highest during the 1929-30 and 1930-31 seasons, when furbearers were abundant and prices were good, and lowest during the 193435 and 1935-36 seasons, when prices were so poor that comparatively few fur-takers cared to operate.

The average total fur income for the 1938-39 and 1939-40 seasons, when the oral survey was made, was about 13 per cent above the average for the 8 years covered by the monthly report study, largely because of price levels and an abundance of muskrats (table 13 of this report and table $t$ of the Brown \& Yeager report). The oral survey showed a calculated average annual income for the seasons of 1938-39 and 1939-40 of $\$ 1$,$201,830.45$ (table 19 of the Brown and Yeager report).

In the 8 years covered by the present study, the average fur-taker sold furs estimated to have an average annual value of about $\$+1$. The annual take per county averaged about $\$ 10,500$.

Muskrats led as income producers year after year, yielding about +7 per cent of the total income over the period of this study. Minks held second place, yielding about 29 per cent of the income over the period. Coons, in third place, produced at least 10 per cent of the income over the study period, but their position

Table 12.-Estimated average annual in. come from common furbearers caught in Illi. nois, beginning with the 1929.30 season and ending with the 1939.40 season $(1931-32,1932$. 33 and 1933-34 omitted because data for these seasons were not available).

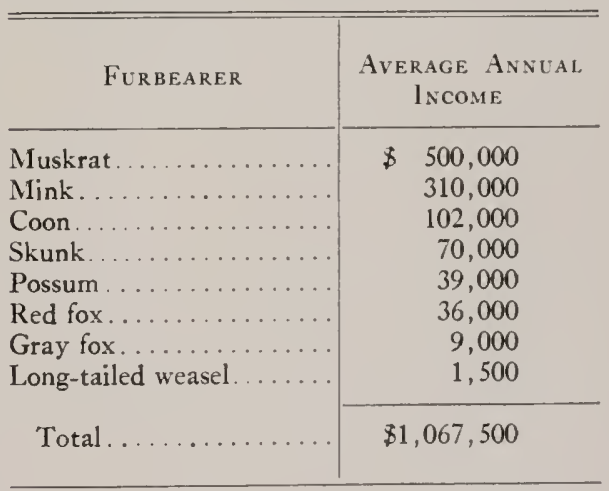

Table 13.-Average prices estimated to have beeen paid for No. 1 medium* pelts of the eight common furbearers of Illinois.

\begin{tabular}{|c|c|c|c|c|c|c|}
\hline FURBEARER & $1929-30$ & $1930-31$ & $1934-35$ & $1935-36$ & $1936-37$ & $1937-38$ \\
\hline 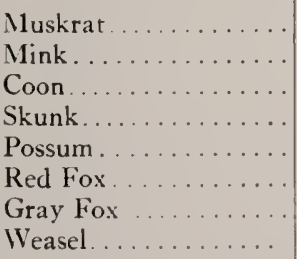 & $\begin{array}{r}\$ 1.00 \\
7.00 \\
5.50 \\
2.40 \\
0.40 \\
10.00 \\
5.00 \\
0.25\end{array}$ & $\begin{array}{l}\$ 0.60 \\
3.50 \\
3.00 \\
1.20 \\
0.35 \\
3.30 \\
3.50 \\
0.25\end{array}$ & $\begin{array}{r}\$ 0.70 \\
4.00 \\
2.50 \\
0.90 \\
0.25 \\
3.30 \\
1.00 \\
0.25\end{array}$ & $\begin{array}{l}\$ 0.60 \\
3.50 \\
2.50 \\
0.90 \\
0.25 \\
2.50 \\
1.30 \\
0.25\end{array}$ & $\begin{array}{r}\$ 0.75 \\
6.50 \\
3.50 \\
1.00 \\
0.30 \\
3.50 \\
1.40 \\
0.25\end{array}$ & $\begin{array}{r}\$ 0.60 \\
5.50 \\
3.50 \\
0.75 \\
0.30 \\
2.80 \\
1.40 \\
0.25\end{array}$ \\
\hline
\end{tabular}

* Prices of No. 1 large pelts are considered too high for calculating income on the average pelt sold. 
fell from about 12 per cent during the $1929-30$ and $1930-31$ seasons to only 6 per cent during the 1938-39 and 1939-40 seasons. Skunks produced about 7 per cent of the income for the period. Possums, although generally caught in greater numbers than skunks, produced less than $t$ per cent of the income, because of relatively low pelt value. Red foxes yielded only about 3 per cent of the income, while gray foxes and long-tailed weasels held the lowest positions among the eight commonly caught furhearers, together producing less than 1 per cent of the income.

Muskrats constituted the leading income producer in most counties, but in some southern counties coons or minks took the lead. Although second place went to minks in most counties, coons and skunks took second place in some.

\section{FUTURE POSSIBILITIES}

It is important to recognize that the fur crop is in addition to all other crops and values realized from Illinois land and waters. In general, it has persisted not because of any favorable attention paid to it but in spite of what has been done. It comes from areas that are growing woods, pastures and even highly cultivated crops; from streams filled with silt and sludge; from ponds so burned or grazed as to be barely suitable for production of anything at all; from land that has been abused so sadly that because of erosion it will no longer grow cultivated crops but has been given up to produce what it can.

If every gully-scar now cutting deeper into Illinois' fields were planted to protecting vegetation, if every woodlot were properly managed by removal of stock and if every stream were kept reasonably clean of silt, sewage and commercial waste, then populations of furbearers, and game as well, would increase.

If the protecting vegetation were scientifically chosen and if protected woodlots were scientifically cut with reasonable attention to needs of furbearer and game populations, then both populations would increase substantially and supplement the income from soil saved and timber produced.

\section{I T E R A T URE CITE D}

\section{Anonymous}

1939. Orter in Illinois. Ill. Cons. 4(2): 16.

1943. Bobcats in Illinois? At least, there were! 11I. Cons. 8(1): 11 .

Bennitt, Rudolf, and Werner O. Nagel

1937. A survey of the resident game and furbearers of Missouri. Mo. Univ. Studies 12(2): 1-215.

Bonnell, Clarence

19+1. The introduction of wild life into southern Illinois. Ill Acad. Sci. Trans. $34(2): 216-7$

Brayton, A. M.

1882. Report on the Mammalia of Ohio. Geol. Surv. Ohio Rept. 4(1):1-185.

Cory, Charles B.

1912. The mammals of Illinois and Wisconsin. Field Mus. Nat. Hist. Zool. Ser. $153(11): 1-505$. Illus.

Driver, E. C.

1930. The fur yield of Illinois. Unpublished manuscript. III. Nat. Hist. Surv:

lorbes, Stephen A.

1912. The native animal resources of the state. Ill. Acad. Sci. Trans. 5:37-48.
Frison, Theodore $\mathrm{H}$.

1931. State Natural History Survey. III. Blue Book 1931-32:387-400. Illus.

1933. Economic problems of Illinois' fields, forests, and streams solved by Natural History Survey. Ill. Blue Book 1933-34: 477-92. Illus.

1938. Advances in the renewable natural resources program of Illinois. Ill. Acad. Sci. Trans. 31(1): 19-3t. 10 figs.

Gregory, Tappan

1936. Mammals of the Chicago region. Chicago Acad. Sci. Prog. Act. 7(2-3): 12-75. Illus., bibliog.

Illinois State Department of Conservation

1935. Game and fish codes of Illinois in force July 1, 1935. $112 \mathrm{pp}$.

1937. Game and fish codes of Illinois in force July 1, 1937. 122 pp.

1939. Game and fish codes of Illinois in force July 1, 1939. 129 pp.

Kennicott, Robert

1855. Catalogue of animals observed in Cook County, Illinois. Ill. State Ag. Soc. Trans. 1 : 577-95. 
1859. The quadrupeds of Illinois, injurious and beneficial to the farmer. U. S. Pat. Off. Rep. Ag. for 1858, pp. 2+156.

Koestner, E. J.

$19+1 a$. Some recent records of central Illinois mammals, report of the Reelfoot Lake Biological Station, 5. Jour. Tenn. Acad. Sci. 16(1): 46-7.

$19+1 b$. Noteworthy records of occurrence of mammals in central Illinois. Ill. Acad. Sci. Trans. 34(2):227-9.

La Due, Harry J.

1935. Guide for trapping and care of raw furs. St. Peter, Minn. 69 pp.

Leopold, Aldo

1929. Game survey of Illinois. Unpublished. 75 pp., maps, appendix.

1931. Report on a game survey of the north central states. Sporting Arms and Ammunition Mfg. Inst., Madison, Wis. 299 pp., illus.

Lyon, Marcus Ward, Jr.

1936. Mammals of Indiana. Am. Midland Nat. $17(1): 1-38+$.

Mohr, Carl O.

1937. Illinois trappers' averages reveal coon and possum distribution. Ill. Cons. 2(t): $3-t, 8$.

1939. 'Trappers' reports reveal furbearer fluctuations in Illinois. Ill. Cons. 4 (1) : t-5. Illus.

19+1. Distribution of Illinois mammals. III. State Acad. Sci. Trans. 34(2) : 229-32. Illus.
Necker, Walter L., and Donald M. Hatfield

19+1. Mammals of Illinois; an annotated check list with keys and bibliography. Chicago Acad. Sci. Bul 6(3):1-60. Illus., bibliog.

Rasmussen, D. I.

1931. Unpublished notes. III. Nat. Hist. Surr.

Scott. Thomas G.

1937. Mammals of lowa. Iowa State Col. Jour. Sci. 12(1): +3-97.

Thatcher, Arthur

1937. Jersey plans county-ivide program of game management. Ill. Cons. 2(2): $10-2$.

U. S. Bureau of Biological Survey

1939. A survey of the annual fur catch of the United States. WVildlife Res. and Mgt. Leaf. BS-I40:1-19. (Mimeographed.)

U. S. Forest Service

1937. Estimate of fur-bearing animals on national forests, 1935-1936. 1 p. (Planographed.)

1938. Estimate of fur-bearing animals on the national forests, 1936-1937. 1 p. (Planographed.)

U. S. Fish and Wildlife Service

1940. The annual fur catch of the United States. U. S. Fish and Wildlife Serv. Wildlife Leaf. 170:1-21. (Mimeographed.)

Wood, Frank Elmer

1910. A study of the mammals of Champaign County, Illinois. Ill. State Lab. Nat. Hist. Bul. 8(5): 501-613. Illus. 



\section{Recent Publications}

\section{of the Illinois Natural History Survey}

\section{A.-ILLINOIS NATURAL HISTORY SURVEY BULLETIN}

Volume 21, Article 3.-Studies of Nearetic Aquatic Insects. By H. H. Ross and T. H. Frison. September, 1937. 52 pp., frontis. +86 figs., bibliog. 50 cents.

Volume 21, Article 4.-Descriptions of Nearctic Caddis Flies (Trichoptera), will special reference to the Illinois species. By Herbert H. Ross. March, 1938. $84 \mathrm{pp}$. frontis. + 123 figs., foreword, index. $\$ 1.00$.

Volume 21, Article 5.-Preliminary Studies on Parasites of Upland Game Birds on Fur-Bearing Mammals in Illinois. By W. Henry Leigh. August, 1940. 10 pp., frontis. +2 maps.

Volume 21, Article 6.-Preliminary Investigation of Oak Diseases in Illinois. By J. Cedric Carter. June, 1941. 36 pp., frontis. +51 figs., bibliog. (Bound with Article 7.)

Volume 21, Article 7.-A Needle Blight of Austrian Pine. By Robert L. Hulbary. June, 1941. 6 pp., frontis. +3 figs., bibliog. (Bound with Article 6.)

Volume 21, Article 8.-Duck Food Plants of the Illinois River Valley. By Frank C. Bellrose, Jr. August, 1941. 44 pp., frontis. + 35 figs., bibliog., appendix.

Volume 22, Article 1. - The Plant Bugs, or Miridae, of Illinois. By Harry H. Knight September, 1941. 234 pp., frontis. + 181 figs., bibliog., index. \$1.25.

Volume 22, Article 2.-Studies of North American Plecoptera, with special reference to the fauna of Illinois. By T. H. Frison. September, 1942. 122 pp., frontis. +126 figs., bibliog., index. $\$ 1.00$.

Volume 22, Article 3.-Management of Small Artificial Lakes: a summary of fisheries investigations, 1938-1942. By George W. Bennett. February, 1943. 20 pp., fronti. +7 figs., bibliog.

Volume 22, Article 4.-The Prairie Chicken in Illinois. By Ralph E. Yeatter. May, 1943. 40 pp., frontis. +18 figs., bibliog. (Bound with Article 5.)

Volume 22, Article 5.-Preferential Rating of Duck Food Plants. By Frank C. Bellrose, Jr., and Harry G. Anderson. May, 1943. 16 pp., frontis. +16 figs., bibliog. (Bound with Article 4.)

\section{B.-ILLINOIS NATURAL HISTORY SURVEY CIRCULAR.}

32.-Pleasure With Plants. By L. R. Tehon. November, 1942. (Second printing, with revisions.) 32 pp., frontis. +9 figs.

33.-Controlling Peach Insects in Illinois. By S. C. Chandler and W. P. Flint. August, 1939. 40 pp., frontis. +32 figs.

34.--Rout the Weeds! Why, When and How. By L. R. Tehon. August, 1943. (Third printing.) 47 pp., color frontis. +13 figs.

35.-Diseases of Small Grain Crops in Illinois. By G. H. Boewe. September, 1939. 130 pp., frontis. +47 figs.

36.-Planting and Care of Shade Trees. By J. E. Davis. March, 1941. 23 pp., frontis. +16 figs.

37. - Outwitting Termites in Illinois. By W. E. McCauley and W. P. Flint. August, 1942. (Second printing.) 23 pp., frontis. +19 figs.

38. - Windbreaks for Illinois Farmsteads. By J. E. Davis. February, 1942. (Second printing.) 24 pp., frontis. + 19 figs.

39. - How to Collect and Preserve Insects. By H. H. Ross. June, 1941. 48 pp., fronti. +53 figs.

40.-Control of Roundheaded Apple Tree Borer. By S. C. Chandler and W. P. Flint. April, 1942. 8 pp., 6 figs.

\section{C.-ILLINOIS NATURAL HISTORY SURVEY MANUAL.}

1. Fieldbook of Illinois Wild Flowers. By the staff. March, 1936. 406 pp., color frontis. +349 figs., index. $\$ 1.50$.

2.-Fieldbook of Illinois Land Snails. By Frank Collins Baker. August, 1939. 166 pp., color frontis. +170 figs., 8 pls. $\$ 1.00$.

3.-Fieldbook of Native Illinois Shrubs. By Leo R. Tehon. December, 1942. 307 pp., 4 color pls. +72 figs., glossary, index. $\$ 1.25$.

List of available publications, over 350 tirles, mailed on request.

Address orders and correspondence to the Chief

ILIINOIS NATURAL HISTORY SURVEY

Natural Resources Building, Urbana, Illinois

Payment in the form of U. S. Post Office money order mado out to Stato Treasurer of Illinois, Springfeld, Ilinols,

nust accompang requests for those publications on which a price is set. 